\title{
In Search of Neural Endophenotypes of Postpartum Psychopathology and Disrupted Maternal Caregiving
}

\author{
E. L. Moses-Kolko*, M. S. Horner*, M. L. Phillips*\$+ A. E. Hipwell*† and J. E. Swain§đ
}

*Department of Psychiatry, Western Psychiatric Institute and Clinic, University of Pittsburgh Medical Center, Pittsburgh, PA, USA.

$\dagger$ Department of Psychology, University of Pittsburgh, Pittsburgh, PA, USA.

$\$$ Department of Psychological Medicine, Cardiff University School of Medicine, Cardiff, UK.

§Departments of Psychiatry and Psychology, Center for Human Growth and Development, University of Michigan, Ann Arbor, MI, USA.

qYale Child Study Center, Yale University, New Haven, CT, USA.

\section{Journal of Neuroendocrinology}

Correspondence to:

Eydie L. Moses-Kolko, Western Psychiatric Institute and Clinic, 3811 O'Hara Street, Pittsburgh, PA 15213, USA (e-mail:mosesel@upmc.edu).
This is a selective review that provides the context for the study of perinatal affective disorder mechanisms and outlines directions for future research. We integrate existing literature along neural networks of interest for affective disorders and maternal caregiving: (i) the salience/fear network; (ii) the executive network; (iii) the reward/social attachment network; and (iv) the default mode network. Extant salience/fear network research reveals disparate responses and corticolimbic coupling to various stimuli based upon a predominantly depressive versus anxious (post-traumatic stress disorder) clinical phenotype. Executive network and default mode connectivity abnormalities have been described in postpartum depression (PPD), although studies are very limited in these domains. Reward/social attachment studies confirm a robust ventral striatal response to infant stimuli, including cry and happy infant faces, which is diminished in depressed, insecurely attached and substance-using mothers. The adverse parenting experiences received and the attachment insecurity of current mothers are factors that are associated with a diminution in infant stimulus-related neural activity similar to that in PPD, and raise the need for additional studies that integrate mood and attachment concepts in larger study samples. Several studies examining functional connectivity in resting state and emotional activation functional magnetic resonance imaging paradigms have revealed attenuated corticolimbic connectivity, which remains an important outcome that requires dissection with increasing precision to better define neural treatment targets. Methodological progress is expected in the coming years in terms of refining clinical phenotypes of interest and experimental paradigms, as well as enlarging samples to facilitate the examination of multiple constructs. Functional imaging promises to determine neural mechanisms underlying maternal psychopathology and impaired caregiving, such that earlier and more precise detection of abnormalities will be possible. Ultimately, the discovery of such mechanisms will promote the refinement of treatment approaches toward maternal affective disturbance, parenting behaviours and the augmentation of parenting resiliency.

Key words: postpartum depression, brain imaging, attachment, caregiving doi: $10.1111 /$ jne. 12183

\section{Introduction}

Because of the seriousness of the adverse negative impact of maternal psychopathology on child development and challenges to effective maternal treatment, there are growing efforts to understand the neurobiology of maternal psychopathology and caregiving deficits, with the objective of establishing biomarkers for illness severity and treatment response. There has been a false dichotomy in the early affective neuroscience literature in mothers, whereby one set of studies focused on standard emotion processing deficits in samples of women with major depression and another set of studies focused on maternal responses to infant cues to inform the neural circuitry of maternal caregiving. A growing number of recent studies have valiantly begun to integrate the complex concepts of 
impaired emotion processing and deficient maternal caregiving. For these latter studies, the design typically consists of populations included for presence or absence of a psychiatric disorder, defined using criteria from the Diagnostic and Statistical Manual (e.g. DSMIV) or related symptom measures, and functional magnetic resonance imaging (fMRI) paradigms typically use ecologically relevant infant and child stimuli, with clinical relevance often demonstrated by correlation with impaired mother-infant interactions. Here, we attempt to summarise and integrate this rich literature along four key neural networks that are consistently described both in the general affective neuroscience literature, as well as the maternal caregiving literature (1): (i) the salience/fear network; (ii) the executive network; (iii) the reward/social attachment network; and (iv) the default mode network. Below, we provide a selective review of each network independently, describing the functional role of each network, as well as what we know about how these networks function in depression and anxiety disorders in nonpostpartum and postpartum populations (Table 1).

\section{Primer on $\mathrm{fMRI}$ activation studies}

Because this review centers on $\mathrm{FMRI}$ studies, we include a brief primer on this technology. The fMRI signal is based upon bloodoxygenation-level-dependent (BOLD) measurements that reflect changes in neural activity over a time resolution of seconds. Typically, BOLD signals during different events are measured throughout the brain. Subsequent analyses identify brain regions that show greater activity in response to a condition of interest (e.g. own baby-cry versus other baby-cry) and allow correlation of such brain activity with measures of psychopathology and parental behaviours. Several caveats of current brain imaging approaches must be considered. First, the BOLD signals of the $\mathrm{fMRI}$ data are indirect measures of neural activity, such that the data are susceptible to non-neural changes in the participant's body and environment. These problems are partially controlled with choice of population and averaging. Second, imaging data provide information on the association, rather than causality, between brain and behaviour. Confidence in associations may be strengthened with multiple lines of inquiry, replication and possible analyses under development that consider connectivity and timing in responses in different circuits. Third, because of the limitations of space and movement in the scanner, fMRI studies must use simple tasks and stimuli to simulate the performance of parenting behaviours. This is addressed by regressing brain activity to real-life parenting and by using increasingly sophisticated and realistic in and out of scanner tasks. Finally, differences in parental brain function are subject to many factors that are not typically controlled, including early-life experiences, postpartum timing, social environment, sleep and hormonal concentrations. Investigators are gradually coming to understand and attempt to control for these variables.

\section{Salience/fear network}

The role of the salience network is to focus the brain's resources on the most important environmental stimuli in the service of guiding future actions that will overcome or circumvent threats to organism homeostasis. As initially described by Seeley et al. (2), the dorsal anterior cingulate cortex (dACC), orbital fronto-insular cortex and anterior insula are the key components of the salience network, which are well-poised to integrate sensory, visceral, autonomic, interoceptive and hedonic data through connections with subcortical (amygdala, striatum, dorsomedial thalamus, hypothalamus) and brainstem structures (periaqueductal gray, substantia nigra and ventral tegmental area). The neural salience network (2) responds in proportion to the degree of personal relevance of a given cue and therefore activates strongly to the social threat of angry/fearful faces $(3)$ and threat of shock $(4,5)$. Moreover, the role of the anterior portion of the insula in interoceptive awareness of emotional stimuli (i.e. sensitivity to internal bodily sensations) and its association with autonomic arousal (6) highlights the putative role of this region in reflecting individual differences in anxious arousal during the processing of threat (7).

Neural systems for processing threat overlap with those in the salience network and encompass, most notably, the amygdala, insula and bed nucleus of the stria terminalis (BNST). The amygdala and BNST show greater activity to negative emotional faces and shock with increasing levels of anxious arousal. It has been demonstrated in rodent models that neural responses to acute versus sustained threat may be anatomically segregated, with amygdala activity increasing to acute threat and BNST activity increasing to sustained threat cues and hypervigilance (8). Heightened BNST responses to the threat of electric shock in proportion to levels of trait anxiety (5) support this notion in humans, although the functional segregation may not be as clear as in rodents given that amygdala also activates strongly in threat-of-shock paradigms. Given the neuroimaging challenges of small size and irregular shape of the BNST, the amygdala has been the subcortical structure most frequently studied in response to stimuli of environmental threat. The amygdala serves a critical gating function and sends efferent neurones to the higher-order sensory cortex to evaluate and respond to threat (9).

In unselected samples, activity within the salience network to negative emotional stimuli correlates with state anxiety (e.g. to a particular situation versus characteristic trait-level anxiety) (2) and is considered to be involved mechanistically in the emotional hyper-reactivity that can evolve into a major depressive episode. Across numerous studies, nonpostpartum individuals with depression, anxiety disorders, trait anxiety and neuroticism have shown increased amygdala activity in response to negative emotional stimuli (10). Specifically, amygdala activation to negative faces has been replicated in major depressive disorder (MDD) (11-18) and is associated with the ruminative quality (19) and negative bias to emotional information in MDD (20) that represents exaggerated responses to negative emotional stimuli. Heightened amygdala activity to negative emotional stimuli $(11-15,17-21)$ may also serve as a marker of persistent effects of past MDD, which was shown in some $(21-23)$ but not other studies $(14,17,24,25)$ of individuals who recovered from depression versus controls.

In human research, important regulatory regions, including $\mathrm{dACC}$, ventral $A C C$ and the dorsomedial prefrontal cortex (DMPFC), are 
Table 1. Functional magnetic resonance imaging (fMRI) Studies of Mothers Highlighting Contrasting Findings in Healthy Mothers Versus Those With Affective Symptoms, Substance Use, or Characteristics Relating to Impaired Attachment Processes.

\begin{tabular}{|c|c|c|c|c|}
\hline Author (year) (reference) & N; Group & $\begin{array}{l}\text { Age of infants/ } \\
\text { children }\end{array}$ & fMRI paradigm & Findings \\
\hline \multicolumn{5}{|l|}{ Salience/fear network } \\
\hline \multicolumn{5}{|l|}{ Healthy mothers } \\
\hline Seifritz et al. (2003) (40) & $\begin{array}{l}\text { 20, mothers versus } \\
\text { women without } \\
\text { children }\end{array}$ & $<3$ years & $\begin{array}{l}\text { Infant cries and laughter } \\
\text { versus control sound }\end{array}$ & $\begin{array}{l}\uparrow \text { Amygdala, middle cingulate } \\
\text { cortex and insula activity in } \\
\text { mothers versus women without } \\
\text { children }\end{array}$ \\
\hline Bartels and Zeki (2004) (45) & 19, mothers & $\begin{array}{l}9 \text { months to } \\
6 \text { years }\end{array}$ & $\begin{array}{l}\text { Face pictures of own versus } \\
\text { unknown/familiar child; } \\
\text { comparison of maternal } \\
\text { versus romantic love }\end{array}$ & $\begin{array}{l}\uparrow \text { Insula and dACC activity to own } \\
\text { child, which overlapped regions } \\
\text { active to romantic others }\end{array}$ \\
\hline Ranote et al. (2004) (101) & 10, mothers & $4-8$ months & $\begin{array}{l}\text { Video of own versus other } \\
\text { infant }\end{array}$ & $\begin{array}{l}\uparrow \text { Amygdala activation to own } \\
\text { infant }\end{array}$ \\
\hline Swain et al. (2008) (42) & $\begin{array}{l}\text { 12, vaginal versus } \\
\text { caesarean section } \\
\text { deliveries }\end{array}$ & 2-4 weeks & Infant-cry (own versus other) & $\begin{array}{l}\uparrow \text { Amygdala activity to infant cry } \\
\text { in women with vaginal versus } \\
\text { caesarean section deliveries }\end{array}$ \\
\hline Lenzi et al. (2009) (114) & $\begin{array}{l}\text { 16, primiparous } \\
\text { mothers }\end{array}$ & 6-12 months & $\begin{array}{l}\text { Viewing and imitating faces of } \\
\text { own versus other child }\end{array}$ & $\begin{array}{l}\uparrow \text { Insula, amygdala and inferior } \\
\text { frontal gyrus activity associated } \\
\text { with increased maternal } \\
\text { empathy }\end{array}$ \\
\hline Strathearn et al. (2013) & $\begin{array}{l}\text { 39, primiparous } \\
\text { mothers }\end{array}$ & $\sim 11$ months & Child faces (own versus other) & $\begin{array}{l}\uparrow \text { Amygdala activity to own } \\
\text { versus other infant faces }\end{array}$ \\
\hline Ho et al. (2014) (216) & 14 , mothers & $\sim 4$ years & $\begin{array}{l}\text { Parenting decision-making } \\
\text { task }\end{array}$ & $\begin{array}{l}\uparrow \text { vACC to +ve versus - ve infant } \\
\text { feedback. Hypothalamus-septal } \\
\text { coupling during - ve feedback } \\
\text { inversely related to cortisol } \\
\text { reactivity }\end{array}$ \\
\hline \multicolumn{5}{|c|}{ Mothers with affective symptoms, substance use or impaired infant interaction } \\
\hline Silverman et al. (2007) (49) & $\begin{array}{l}\text { 8, postpartum mothers } \\
\text { with EPDS }>12 \text { or } \\
<6\end{array}$ & 7-8 weeks & Negative emotional words & $\begin{array}{l}\downarrow \text { Amygdala but } \uparrow \text { insula activity } \\
\text { to negative words in women } \\
\text { with EPDS }>12\end{array}$ \\
\hline Moses-Kolko et al. (2010) (50) & 30, PPD versus $\mathrm{HC}$ & $8-10$ weeks & Fear/threat adult faces & $\begin{array}{l}\downarrow \text { DMPFC activity and amygdala- } \\
\text { DMPFC connectivity in PPD } \\
\downarrow \text { Amygdala activity associated } \\
\text { with postpartum depression } \\
\text { severity }\end{array}$ \\
\hline Laurent \& Ablow (2012) (43) & 22, PDD versus $\mathrm{HC}$ & 18 months & Infant-cry (own versus other) & $\downarrow d A C C$ and insula activity in PPD \\
\hline Barrett et al. (2012) (39) & $\begin{array}{l}\text { 22, mothers, varied } \\
\text { affective symptoms }\end{array}$ & $\sim 3$ months & $\begin{array}{l}\text { Infant faces (own versus } \\
\text { other), with affect rating } \\
\text { task }\end{array}$ & $\begin{array}{l}\downarrow \text { Amygdala activation to positive } \\
\text { own infant faces associated with } \\
\text { more depression (EPDS) and } \\
\text { anxiety symptoms (STAI-trait) }\end{array}$ \\
\hline Schechter et al. (2012) (61) & $\begin{array}{l}\text { 20, IPV-PTSD versus } \\
\text { control }\end{array}$ & 12-42 months & $\begin{array}{l}\text { Videos of child stress during } \\
\text { separation (own versus other } \\
\text { child) }\end{array}$ & $\begin{array}{l}\uparrow \text { Insula and } \downarrow \text { mPFC activity to } \\
\text { child separation videos that } \\
\text { correlated with self-reported } \\
\text { stress }\end{array}$ \\
\hline Moser et al. (2013) (63) & 20, IPV-PTSD & 12-42 months & $\begin{array}{l}\text { Videos of child stress with } \\
\text { separation (own versus other } \\
\text { child) }\end{array}$ & $\begin{array}{l}\downarrow \text { Cingulate, hippocampus and } \uparrow \\
\text { DLPFC activity to child } \\
\text { separation videos associated } \\
\text { with greater dissociative } \\
\text { symptoms }\end{array}$ \\
\hline Landi et al. (2011) (128) & $\begin{array}{l}\text { 54, substance using } \\
\text { versus non-using } \\
\text { postpartum mothers }\end{array}$ & $1-3$ months & $\begin{array}{l}\text { Infant sad faces, low distress } \\
\text { cries (all other infants) }\end{array}$ & $\begin{array}{l}\downarrow \text { Amygdala, parahippocampus, } \\
\text { insula, lateral PFC, activity in } \\
\text { substance users }\end{array}$ \\
\hline
\end{tabular}


Table 1 (continued)

\begin{tabular}{|c|c|c|c|c|}
\hline Author (year) (reference) & $\mathrm{N} ;$ Group & $\begin{array}{l}\text { Age of infants/ } \\
\text { children }\end{array}$ & fMRI paradigm & Findings \\
\hline Musser et al. (2012) (157) & $\begin{array}{l}\text { 22, primiparous, varied } \\
\text { maternal sensitivity }\end{array}$ & 18 months & $\begin{array}{l}\text { Infant-cry (own versus other } \\
\text { versus control sounds) }\end{array}$ & $\begin{array}{l}\downarrow \text { IFG and } \uparrow \text { insula activity } \\
\text { associated with reduced } \\
\text { maternal sensitivity and } \\
\text { increased maternal intrusiveness }\end{array}$ \\
\hline Laurent et al. (2012) (156) & $\begin{array}{l}\text { 22, primiparous } \\
\text { mothers }\end{array}$ & 15-18 months & $\begin{array}{l}\text { Infant-cry (own versus control } \\
\text { sound) }\end{array}$ & $\begin{array}{l}\uparrow \text { Parahippocampus/amygdala and } \\
\text { insula activity to cry in mothers } \\
\text { of insecurely-attached infants }\end{array}$ \\
\hline Author (year) (reference) & $\mathrm{N}$; Group & $\begin{array}{l}\text { Age of infants/ } \\
\text { children }\end{array}$ & Paradigm, variable & Regional findings \\
\hline
\end{tabular}

\section{Executive network}

Healthy postpartum versus menstruating nonpostpartum women

Bannbers et al. (2013) (76) 26; postpartum versus 48 h; 4-7 weeks Go/NoGo task

\section{Reward/social attachment network}

\section{Healthy mothers}

Lorberbaum et al. (2002) (41)

Bartels and Zeki (2004) (45)

Leibenluft et al. (2004) (44)

7, mothers

Noriuchi et al. (2008) (37)

13 , mothers

Strathearn et at. (2008) (38)

26, primiparous

mothers

12 , vaginal versus caesarean section deliveries (VD)

Kim et al. (2011) (48)

$$
\begin{aligned}
& \text { 17, breast- versus } \\
& \text { formula-feeding } \\
& \text { mothers }
\end{aligned}
$$

Infant-cry (other) versus white noise versus baseline rest

Face pictures of own versus unknown/familiar child

Child faces (own versus familiar/unfamiliar other)

Video clips own versus other infant

Child happy faces (own versus other)

2-4 weeks

Infant-cry (own versus other)

\begin{tabular}{|c|c|c|c|}
\hline Silverman et al. (2007) (49) & $\begin{array}{l}\text { 8, postpartum mothers } \\
\text { with EPDS }>12 \text { or } \\
<6\end{array}$ & 7-8 weeks & Positive emotional words \\
\hline Strathearn et al. (2009) (46) & $\begin{array}{l}\text { 30, primiparous } \\
\text { mothers }\end{array}$ & $\sim 11$ months & $\begin{array}{l}\text { Child happy faces (own versus } \\
\text { other) }\end{array}$ \\
\hline
\end{tabular}

Infant-cry (own versus other)

Mothers with affective symptom, impaired infant interaction, or low maternal care received, insecure attachment $\downarrow$ VLPFC, precentral gyrus, and dACC at later versus early postpartum timepoints and relative to nonpostpartum women

$\uparrow$ Medial thalamus, medial PFC, right OFC to infant cry

$\uparrow$ Striatum, thalamus, PAG to own child

$\uparrow$ Mentalising circuitry (DMPFC, MPFC, PCC, TPJ, pSTS) to own child $>$ familiar/unknown child $\uparrow$ OFC, periaqueductal gray, putamen to own infant

$\uparrow$ Putamen, SN, thalamus, amygdala to own versus other faces

$\uparrow \mathrm{SFG}$, caudate and thalamus to infant cry in women with vaginal versus caesarean section deliveries. Correlation of parental preoccupation with lenticular nucleus activation

$\uparrow$ SFG, insula, precuneus, striatum, and amygdala activity to own infant cry in breast- versus formula-feeding mothers $\uparrow$ Maternal sensitivity associated with increased SFG and amygdala activity

$\downarrow$ Striatum to positive words in women with EPDS $>12$

$\downarrow$ VST, OFC, mPFC activity to faces in mothers without secure attachment 
Table 1 (continued)

\begin{tabular}{|c|c|c|c|c|}
\hline Author (year) (reference) & N; Group & $\begin{array}{l}\text { Age of infants/ } \\
\text { children }\end{array}$ & Paradigm, variable & Regional findings \\
\hline Kim et al. (2010) (53) & 26, mothers & 2-4 weeks & $\begin{array}{l}\text { Infant-cry (other versus } \\
\text { control sound) }\end{array}$ & $\begin{array}{l}\downarrow \text { MFG, STS and fusiform gyrus to } \\
\text { infant cry for women with a } \\
\text { history of lower maternal care } \\
\text { received }\end{array}$ \\
\hline $\begin{array}{l}\text { Moses-Kolko et al. } \\
\text { (2011) (105) }\end{array}$ & 24, PPD versus $\mathrm{HC}$ & 8-10 weeks & Monetary reward task & $\begin{array}{l}\downarrow \text { Ventral striatal duration of } \\
\text { reward-related response in PPD }\end{array}$ \\
\hline Laurent \& Ablow (2011) (43) & 22, PDD versus $\mathrm{HC}$ & 18 months & $\begin{array}{l}\text { Infant-cry (own versus control } \\
\text { sound) }\end{array}$ & $\begin{array}{l}\downarrow \text { Thalamus, caudate, OFC, SFG in } \\
\text { PPD, and in association with } \\
\text { higher CESD scores }\end{array}$ \\
\hline Atzil et al. (2011) (125) & 23, mothers & 4-6 months & $\begin{array}{l}\text { Mother-infant interaction } \\
\text { videos (self versus other } \\
\text { mother-infant dyad) }\end{array}$ & $\begin{array}{l}\uparrow \text { Striatal activity associated with } \\
\text { greater mother-infant behavioral } \\
\text { synchrony }\end{array}$ \\
\hline \multicolumn{5}{|l|}{ Default mode network } \\
\hline \multicolumn{5}{|l|}{ Depressed versus healthy mothers } \\
\hline Xiao-juan et al. (2011) (147) & 21, PPD versus $\mathrm{HC}$ & Within 16 weeks & Resting state & $\begin{array}{l}\uparrow \text { PCC index of nearest neighbor } \\
\text { connectivity (ReHo) in PPD }\end{array}$ \\
\hline Chase et al. (2013) (144) & 37, PPD versus $\mathrm{HC}$ & 10 weeks & Resting state & $\begin{array}{l}\downarrow \text { PCC-amygdala connectivity in } \\
\text { PPD }\end{array}$ \\
\hline $\begin{array}{l}\text { Deligiannidis et al. } \\
\text { (2013) (146) }\end{array}$ & 17, PPD versus $\mathrm{HC}$ & 9 weeks & Resting state & $\begin{array}{l}\downarrow \text { Connectivity within } \\
\text { corticolimbic circuits including } \\
\text { the default mode network }\end{array}$ \\
\hline
\end{tabular}

CESD, Center for Epidemiologic Studies Depression Scale; dACC, dorsal anterior cingulate cortex; DMPFC, dorsomedial prefrontal cortex; EPDS, Edinburgh Postnatal Scale for Depression; HC, healthy controls; IFG, inferior frontal gyrus; IPV-PTSD, interpersonal violence-related post-traumatic stress disorder; MPFC, medial prefrontal cortex; OFC, orbitofrontal cortex; OT, oxytocin; PAG, periaqueductal gray; PCC, posterior cingulate cortex; PPD, postpartum depression; pSTS, posterior superior temporal sulcus; ReHo, regional homogeneity or synchronisation between time series of a voxel with that of its nearest neighbors; SFG, superior frontal gyrus; SN, substantia nigra; STAI, Speilberger State Trait Anxiety Inventory; TPJ, temporal-parietal junction; VE, valence. References are listed chronologically. In cases where references have findings that relate to multiple networks, such references have been categorised according to the most relevant network and, in some cases, are listed in two categories if more than one network is adequately assessed.

active during the perception of emotionally salient and threatening stimuli, such as electric shock. Indeed, a deficit in the regulatory ability of amygdala by medial PFC structures is a widely described mechanism for increased attention to threat, with different patterns of medial PFC-amygdala coupling associated with different anxiety constructs. Generalised anxiety disorder, for example, is associated with decreased functional connectivity between the ventral ACC and amygdala during implicit emotion regulation $(26,27)$, which is considered to represent insufficient regulation of threat. Higher trait anxiety may be associated with greater functional connectivity between DMPFC/dACC and amygdala, denoting increased attention to threat, a circuit of DMPFC-amygdala positive connectivity. Robinson et al. (28) describe this circuit as an 'aversive amplification' mechanism whereby threat-responding is increased in the service of protecting the individual from harm.

In rodent studies of early motherhood, the fear and threat circuitry is attenuated in the service of facilitating maternal interaction with, and care/protection of, her offspring. Reduced fear and stress responses in puerperal rodents are associated with decreased amygdala c-fos synthesis (compared to nonpuerperal rodents) (29) and are attributed to increased puerperal amygdalar prolactin and oxytocin inputs (30-32). A novel paradigm that used functional neuroimaging in awake postpartum rodents to examine regional brain BOLD in response to threatening cues revealed that intracerebral oxytocin infusion was associated with an increased percentage BOLD change (threatening cue versus rest) in BNST (33), which may relate to oxytocin-mediated inhibitory neural activity in fear response centers. In a similar paradigm, arginine vasopressin circuits were also shown to influence the degree of neural responses to threat in amygdala (34). A reduction of fear responses in newly maternal rodents is inversely related to an increase of maternal aggression (see also section on Reward/social-attachment network, below) in the service of protection of the offspring, which are functions mediated via brain interactions with prolactin, oxytocin, arginine vasopressin and the hypothalamic-pituitary-adrenal (HPA) axis (35). For example, blockade of arginine vasopressin receptors was found to increase maternal aggression by suppressing amygdala and increasing olfactory and infralimbic activity $(34,36)$.

Functional MRI studies of human mothers have rarely been acquired in the immediate postpartum period. At 2-week or more distal postpartum timeframes, a number of studies have examined healthy mothers responding to negative emotional infant stimuli, including video clips of infants in distress (37), pictures of sad infant faces $(38,39)$ and infant cries $(40-43)$. These studies have revealed that negative infant stimuli activated the amygdala $(40,42)$ (in addition to broader maternal circuitry; see below) which has 
often been interpreted as a sign of emotional salience (40) or positive emotion associated with attachment (44). One notable exception was a report of amygdala deactivation to own infant pictures (45), which was interpreted as an 'evolutionarily protective mechanism to invest more energy into reward-oriented rather than fearoriented emotions and behaviours in motherhood'. Mothers with insecure adult attachment (46), recurrent MDD since adolescence (43), higher levels of depression and anxiety symptoms (39) and psychopathological risk factors (47), as well as mothers with fewer oxytocin/prolactin-stimulating functions [cesarean section deliveries (42) and bottle-feeding (48)], had less robust amygdala activity to infant-cry stimuli.

Two additional studies $(49,50)$ of mothers attending to noninfant negative emotional stimuli found that PPD versus healthy status and greater PPD severity was associated with reduced amygdala activity to fearful and threatening faces or negatively valenced words. Taken together, these studies suggest a relatively consistent picture of blunted amygdala activity to negative emotional stimuli and infant distress stimuli among mothers with more depressive and anxious affect, less secure attachment styles, and less prosocial hormone availability.

Little is known about cortical brain regions that directly modulate limbic reactivity to infant and other emotional cues in postpartum women because few studies of within-circuit connectivity have been published. In a single example of such a study, postpartum depressed women demonstrated an absence or disengagement of DMPFC- amygdala connectivity when viewing fearful and threatening faces, whereas healthy mothers had intact DMPFC-amygdala connectivity to fearful and threatening faces (50). The activation of DMPFC to infant-cry $(41,43)$, to distressed infant videos $(37)$ and to own child greater than to familiar/unknown faces (44) advances a role for areas of covert appraisal and social cognition in healthy maternal behaviour. A single, small study $(n=8)$ revealed reduced posterior orbitofrontal cortex (OFC) activity to negative words in women with PPD compared to healthy postpartum women (49). Furthermore, Laurent and Ablow (43) reported that higher depressive symptoms (Center for Epidemiologic Studies Depression Scale) and a diagnosis of MDD were associated with lower left OFC, dACC and medial superior frontal gyrus (SFG) activity to infant-cry. The available data therefore suggest that women with PPD disengage critical cortico-limbic neurocircuitry that is involved in emotional salience and threat processing during exposure to infant and negative affective stimuli. This requires further examination with techniques for analysing within-circuit regional connectivity.

An important exception, however, is provided by the findings of Swain et al. (42), in which heightened lenticular nucleus and left medial PFC activity to own baby-cry was associated with more depressive symptoms and more anxious intrusive thoughts in a group of 12 mothers scanned 3 weeks postpartum on average. Swain et al. (42) argue for a potentially adaptive function subserved by these apparent anxious/depressive symptoms in nondepressed mothers in the early postpartum mother that is not directly comparable to findings in mothers who are three or more months postpartum. In other studies, Swain et al. $(51,52)$ suggest that maternal neural responses to infant stimuli change with the time since delivery, with a diminution of anxiety-related subcortical responses and an increase in regulatory cortical responses to infant-cry among healthy mothers. Indeed, both human (53) and rodent (54) maternal brain research reveal postpartum structural brain growth in orbitofrontal and temporal cortices that may reflect social learning in parents in preparation for changing baby signals over time in addition to the increasingly complex array of possible interactional scenarios. This also opens windows into domains of dysfunction when these adaptations fail to occur, leaving new parents underprepared to respond to increasingly complex situations. Therefore, postpartum duration-dependent analysis of fear/salience network activity and PFC modulatory networks is an important area in need of future investigation.

\section{Summary point}

These studies indicate that mothers with syndromal level depression, less secure attachment styles and less pro-social hormone availability have blunted amygdala and insula activity to negative emotional stimuli and infant distress stimuli, which is the opposite of that described in nonpostpartum depressed samples. Heightened intrusive/anxious responses that accompany subsyndromal affective symptoms in very early ( 3 weeks) postpartum mothers, associated with medial PFC and lenticular nucleus activity to infant-cry, may also serve an adaptive role in attaching to the infant that awaits replication.

Post-traumatic stress disorder (PTSD) is an affective disorder with a unique neurobiology for which there are reports, in non-postpartum samples, of increased insula and amygdala activity when listening to traumatic audio clips in the scanner (55). Ventral and dorsal regions of the ACC activity are noted to variably deactivate or activate in association with threat appraisal (56), depending upon the presence of dissociative symptoms (57). Dissociative-type PTSD or individuals with high scores on the Dissociative Experiences Scale demonstrate increased inhibitory modulation of amygdala and insula by the ventromedial prefrontal cortex (VMPFC) and ventral ACC, which suppresses re-experiencing and hyperarousal symptoms and thus constitutes an effective strategy for diminishing attention to threat by keeping threat segregated from other cognitive processes. These and other mechanisms that distinguish PTSD from MDD may also relate to respective differences in HPA axis function (58). In general, individuals with MDD display HPA axis hyperreactivity, reported as increased baseline cortisol, exaggerated cortisol response to ACTH and non-suppression of the dexamethasone suppression test (DST) (59). By contrast, individuals with PTSD have evidence of HPA axis hyporeactivity, highlighted by a recent meta-analysis showing lower daily cortisol output and lower postDST cortisol in PTSD compared to healthy controls (60).

Similar to non-postpartum populations, but in contrast to anxious and depressed postpartum mothers, 12-48-month postpartum mothers with PTSD secondary to adult interpersonal violencerelated PTSD (IPV-PTSD) had heightened subcortical responses in the fear circuitry. In their elegant study of mothers viewing their own and other child separation versus free play videos, Schechter et al. (61) found that IPV-PTSD mothers activated an 'unrestrained' 
fear-circuitry that was associated with higher subjective ratings of stress. The circuitry described included heightened activity in bilateral anterior entorhinal cortex, left caudate, left insula and reduced frontocortical activity [SFG, Brodmann area (BA) 8, BA10; bilateral superior parietal lobes, BA7] in women with IPV-PTSD compared to healthy mothers. Stress, as measured by the Clinically Administered PTSD Scale and the PTSD Symptom Checklist-short version, was inversely correlated with SFG (BA10) activity and positively associated with caudate activity. Based upon behavioural data in this same population (62), it was suggested that hyperactivity within the fear circuitry associated with IPV-PTSD might mediate reduced maternal emotional availability for coordinated joint attention during play. A sub-analysis within this dataset (63) demonstrated that dissociative symptoms, when present with or without PTSD, were associated with increased cortical (right dorsolateral PFC, 'DLPFC') and decreased limbic activity (perirhinal cortex, hippocampus, insula) to separation versus play videos, as has been found previously in other PTSD-dissociative-subtype populations viewing traumatic and nonspecific negative emotional stimuli (64). These findings highlight the importance of clinical characterisation along lines of intersecting dimensions, such as dissociation, PTSD symptoms and other domains of cognitive function that affect maternal sensitivity and child outcome.

\section{Summary point}

Mothers, more than 1 year postpartum, who have IPV-PTSD, have a neurobiology that resembles PTSD in nonpostpartum populations, as characterised by hyperactivity within the fear circuitry (amygdala and anterior insula) and alternatively decreased or increased (dissociative-type) voluntary VMPFC/ventral ACC regulation of subcortical activity.

\section{Executive network}

As described above, prefrontal cortical regions are involved in the threat processing circuitry with a primary function of regulating activity in subcortical structures. A number of these regulatory regions comprise the executive network, which comes online both during emotional processing tasks and also during performance of attention, working memory and response inhibition tasks. This network primarily includes the DLPFC, the lateral/inferior parietal cortex, and the $\mathrm{dACC} / \mathrm{DMPFC}$ region, with projections to hippocampus. Activity within the executive network is associated with task performance (2).

The executive dysfunction described in MDD has been associated with altered prefrontal executive network activity on common cognitive neuroscience performance tasks, such as the 'Go/No-Go Association Task', testing behavioural inhibition, and the ' $n$-BACK task', measuring cognitive control $(65,66)$. Convergent studies have described decreased activity in emotion regulatory regions including DLPFC, DMPFC and VMPFC $(19,67-70)$, as well as alterations in corticolimbic connectivity during processing of negative faces in unipolar and bipolar depression $(71,72)$. Reduced prefrontal neural activity may normalise following effective depression treatment, such as with transcranial magnetic stimulation (73), and also predict the antidepressant treatment response.

Based upon the evidence of reduced cognitive function in healthy postpartum women $(74,75)$, Bannbers et al. (76) conducted a recent study of response inhibition using the Go/No-Go task to explore a hormone-linked neural basis for this clinical phenomenon. They found that healthy postpartum women showed reduced ventrolateral PFC (VLPFC) activity relative to nonpostpartum women (without concomitant difference in behavioural performance), as well as a lessening over the course postpartum (on average $28 \mathrm{~h}$ postpartum and repeated at 34 days postpartum) of task-related VLPFC and dACC activity. This suggests that healthy postpartum women might be operating at a disadvantage for cognitive and emotion-regulatory functions. It is possible that hormone-related blood flow effects could influence these conclusions given similar findings of lower regional activity in follicular (low hormone state) versus luteal (high hormone state) phase (77) and the role of fluctuating neurohormone concentrations in parental response to baby-cry, suckling and baby-smile $(78,79)$. In addition, the early postpartum timeframe has a number of confounding physiological effects that may contribute to altered signal. These intriguing preliminary findings merit continued study, as well as extension to additional executive function cortical regions. In the salience/fear network section above, we describe deficient prefrontal cortical activity in depressed relative to healthy mothers when processing emotional and infant stimuli. Additional studies, both in healthy and depressed postpartum women, are needed to clarify the relationships between duration postpartum, executive function, emotion regulation and affective symptoms.

\section{Summary point}

Although little research on executive networks has been conducted in postpartum women to date, this is an area ripe for investigation given the critical role for planning, organisation and attention in parenting and known deficits in affective disorders more broadly.

\section{Reward/social-attachment network}

The cortico-striatal-thalamic-cortical loop is a neural circuit that integrates the emotional, behavioural and endocrine aspects of motivated behaviour (80). Together with extrastriatal afferents, dopaminergic output from the ventral tegmental area to the extended ventral striatum (encompassing nucleus accumbens, ventral caudate and putamen) modulates the reinforcing effects of stimuli $(81,82)$. In healthy subjects, fMRI tasks that include anticipation and receipt of monetary rewards have been associated with strong striatal activation (83), whereas medial prefrontal cortex (mPFC) regions, such as VMPFC, are activated during learning of reward-based contingencies (84).

The reward or hedonic neural circuitry has been of great interest to depression researchers because reduced positive affect, in addition to increased negative affect, is an increasingly recognised feature of depressive disorders. Convergent behavioural studies have revealed reduced pursuit and savouring of reward in MDD (85) and 
molecular imaging and preclinical studies provide evidence that this is mediated by aberrant dopamine signalling in the mesostriatal system (86). The results suggest that behavioural reductions in reward-seeking and pleasure are mediated by hypoactivation of ventral striatum to different aspects of reward $(85,87,88)$ and pleasant stimuli (89-91). In several studies of happy faces processing in nonpostpartum populations, it appears that increased VMPFC activity to happy faces is associated with risk for (92) or the presence of (93) mood and anxiety disturbance and might over-regulate striatal responses to positive cues. Therefore, happy faces might be an important social reward cue that can tap into this neural circuitry.

Increased overall dopaminergic tone in parous rodents and postpartum women has been repeatedly described (94) and is considered to be amplified via oxytocinergic inputs to the mesostriatal reward system. The dopamine reward system plays an important role in maternal care insofar as it motivates mother-infant interaction and facilitates the reinforcing aspects of caregiving. Maternalpup caregiving is both temporally and quantitatively correlated with increased extracellular dopamine in the nucleus accumbens (95) and suckling of pups is a more powerful reinforcer for mothers than cocaine administration (96). Interactions between central oxytocin and dopamine systems have also been associated with individual differences in maternal behaviour in rodents. For example, stable, individual differences in rat maternal licking/grooming of pups were abolished by oxytocin receptor blockade and this effect was mediated by the direct effect of oxytocin on dopamine release within the mesocorticolimbic dopamine system (97). Other lines of research have explored the neural basis of maternal aggression, a behaviour that promotes offspring protectiveness and is modulated by oxytocin, arginine vasopression and HPA axis activity. Functional MRI paradigms in awake postpartum rodents subjected to intruder stresses to detect maternal aggression have revealed an important role for periaqueductal gray and nucleus accumbens in maternal aggression (36,98-100).

Functional MRI studies of healthy mothers confirm activation of the mesostriatocortical reward circuitry when mothers listen to cries or view pictures of infant stimuli. In healthy, primiparous, breastfeeding, 4-8-week postpartum mothers listening to a standard infant-cry, fMRI BOLD activations were present in the midbrain, thalamus, striatum and medial PFC (41). Mothers, 2-4 weeks postpartum, who delivered vaginally rather than surgically (and thus experienced oxytocin release during labour and delivery), had greater caudate and thalamic activation to own baby cries (42).

In a study of maternal response to infant face stimuli, maternal responses to own versus other child pictures similarly activated the reward circuit, including the putamen, thalamus and substantia nigra. Robustness of brain activation to infant face stimuli was highest for happy infant faces and progressively lower for neutral and sad infant faces (38). Similar reward system activation was noted in other studies of mothers viewing their children $(37,44,45)$ but not all studies of maternal responses to child faces $(101,102)$. Variations in fMRI stimuli, age of children and maternal characteristics (delivery mode, breastfeeding, parity, support system, etc.) and generally small sample sizes likely account for inconsistencies among studies.
Dopamine-reward circuit dysregulation in PPD has been hypothesised based upon heightened neuroendocrine response to the dopamine receptor agonist apomorphine in women who later experienced postpartum mood disorders (103) and altered ventral striatal dopamine-2 receptor binding in healthy and depressed mothers (104). Functional MRI studies to date in PPD samples demonstrate reduced ventral striatal responses to pleasant words (49) and monetary stimuli (105), which may signal impaired maternal pleasure from, and attunement to, infants in the context of PPD. In addition, maternal ventral striatal responses to own versus other baby-cry at 18 months postpartum were inversely associated with postpartum depression severity (43).

\section{Summary point}

Similar to basic research showing that oxytocinergic inputs to the mesostriatal dopamine reward system enhance maternal motivation and behaviour, healthy mothers have increased ventral striatal and medial PFC activity in response to infant stimuli. Reward-related neural responses to positive words and monetary gain are noted to be reduced in depressed mothers.

\section{Social attachment/social cognition}

Social affiliation, social cognition and reward circuits are closely linked systems that facilitate maternal-infant caregiving. A fundamental component of human mothering is being able to mentalise, that is, to understand the thoughts, beliefs and intentions of others in relation to oneself $(106,107)$. Parental social cognition/ mentalising/empathy involves appropriate perception, experience and response to another's emotion and is particularly relevant to maternal caregiving for pre-verbal infants who cannot articulate their needs. Autistic disorders have shed light on the neural systems supporting empathy (108-110), which overlap substantially with brain responses of parents to infant stimuli, and include cingulate and insular cortices (111). Experiments that compare pain perception in oneself or in a loved one reveal that parallel representations of empathy in insula and ACC are necessary for our ability to mentalise. Humans may utilise separate circuitry to 'decouple' representations of external versus internal information to understand physical properties and assess personal emotional values. In support of this, a brain network consistently activated during tasks that require mentalising has emerged, including DMPFC, mPFC, precuneus/posterior cingulate cortex (PCC), temporoparietal junction (TPJ) and posterior superior temporal sulcus (pSTS) (112,113).

This social cognition circuitry was activated in healthy mothers when viewing photographs of their own children versus familiar children (44). A novel study (114) tapped into these constructs through an FMRI paradigm in which mothers observed and imitated faces of their own and other children. The study specifically examined the mirror neurone system, localised in the ventral premotor cortex, inferior frontal gyrus (IFG) and posterior parietal cortex, which activates not only when an individual performs an action, but also when observing someone else perform that action. Neural 
activation in the mirror neurone system was preferentially engaged in response to own child and was correlated with maternal reflective function. Such a mentalising framework promises to facilitate behavioural planning for parent-infant dyads and likely has farreaching impacts upon maternal and child physical and mental health $(115,116)$.

The development of empathy in parents depends in great part on the care that they themselves received in childhood (117), (see section on Integrative concepts which transcend a neural network approach, below) which is a concept that has been well-elaborated $(118,119)$. Using this framework of analysis, one study examined the effects of early-life experience among mothers in the first postpartum month on brain structure and functional responses to salient infant stimuli (120). Mothers who reported higher perceived maternal care in childhood showed larger grey matter volumes in the superior and middle frontal gyri, orbital gyrus, superior temporal gyrus and fusiform gyrus. In response to infant cries, these mothers also exhibited higher activations in the middle frontal gyrus, superior temporal gyrus and fusiform gyrus, which are all regions involved in processing emotional information and mentalising functions. These findings suggest that an attenuation of maternal care in childhood may be associated with deficits in brain physiology implicated in an appropriate responsivity to infant stimuli in human mothers.

Additionally, the development of secure attachment at a young age in parents promotes healthy dyadic relationships between parent and their social supports and between parent and child. The modulation of threat by secure attachment is well-articulated in social baseline theory (121), which describes how humans evolved to 'outsource' neural demands of threat to supportive social resources. By contrast, isolation demands more individual neural resources to regulate threat. This theory is supported by findings that proximity of a significant other or romantic attachment reduces threat-related neural activity in right anterior insula, SFG and hypothalamus (122) and that perceived social support moderates the relationship between threat-related amygdala activity and trait anxiety (123). Oxytocinergic mechanisms have been proposed to mediate the attenuation of threat-related neural activity by secure attachment (122). The significant spatial overlap of affiliation and emotion-processing neural circuitries in humans (124) gives further support for the functional integration of systems of attachment and threat modulation.

Although animal models of maternal behaviour are compelling and have identified key components of putative mothering circuits, paradigms in animal studies are typically approximations of complex human behaviours and ethological relevance is limited. Nevertheless, rodents and nonhuman primate studies that incorporate social stressors have increasing relevance for informing human psychopathology. For example, recent advances allow for fMRI in awake rats, permitting real-time imaging of social paradigms such as introducing a male intruder to a postpartum rodent with and without pups present to study neural correlates of maternal aggression (36).

Although social cognition and mentalising functions have not been tested directly in postpartum affective disorders, mothers with secure, as opposed to insecure, attachment style had increased activity in dopaminergic-rich ventral striatum, as well as reward-processing OFC and $\mathrm{mPFC}$ regions, to happy infant faces (46). Insecurely attached mothers showed greater DLPFC activity to infant faces, which concurs with the behavioural phenomenon of avoidance of negative affect, and suggests over-regulation, as predicted by the social baseline theory. Similarly, in a study of 'synchronous' and 'intrusive' mothers (based upon microcoding of videotaped mother-infant interaction), synchronous mothers, who consistently coordinate positive social processes with their infant, had increased striatal responses to videos of mother-infant interactions (125). Video clips of mother-infant videos have also been used as stimuli to identify relationships for mothers and fathers between amygdala activity and serum oxytocin and vasopressin, respectively (126). However, in this experiment, it is unclear whether this pattern of brain response was a function of synchronous mothers or the viewing of a synchronous mother-infant interaction. More studies will need to characterise the stimuli, as well as the mothers, in increasing detail to disentangle possible confounds.

Substance-using mothers are a unique sample in which to examine the neural basis for documented disruptions in motherchild relationships (127) and empathic failures. Landi et al. (128) investigated neural correlates to infant cries of varying levels of distress and to infant faces of varying emotional expressions (happy, sad, neutral) among substance-using and nonsubstanceusing mothers at 1-3 months postpartum. With one minor exception, no brain regions showed greater activation in substanceusing mothers compared to non-using mothers in any of the conditions displaying happy, sad or neutral faces. By contrast, nonsubstance-using mothers showed greater activation in a range of prefrontal regions [e.g. DLPFC/medial frontal gyrus (MFG), VMPFC, DMPFC, IFG], limbic system regions (e.g. amygdala, parahippocampal gyrus) and visual/sensorimotor regions for happy, sad and neutral faces compared to substance-using mothers. For cries of both low and high distress, regions involved in emotional processing (amygdala, insula, parahippocampal gyrus), prefrontal regions (MFG) and regions implicated in auditory/sensorimotor processing showed greater activation among non-using mothers than among substance-using mothers. Because these regions comprise networks supporting emotion reactivity and regulation, and are identified as more active in healthy mothers when viewing infant stimuli, substance-using mothers appear to be characterised by a hyporeactivity to visual and auditory infant cues. Thus, blunted neural activity may reduce the salience of cues and contribute to the maladaptive parental responses observed among substance-using mothers. Prenatal foetal exposure to substance use, maternal comorbidities of depression and other psychiatric disorders, and substance use-related high-risk behaviour further compound disrupted maternal care, likely resulting in adverse outcomes for offspring. Further research is needed to explore the extent to which substance use treatments, such as opioid maintenance treatment, compared to high-risk drug-seeking behaviours, confer psychosocial and, potentially, neural benefits through modulation of reward-related behaviours (129). 


\section{Summary point}

Empathy and mentalisation maternal functions are supported by neural systems including insula, ventral ACC, DMPFC, precuneus/ PCC, TPJ and pSTS. The mirror neurone system, localised in the ventral premotor cortex, IFG and posterior parietal cortex, is also involved in maternal reflective function. These regions, in addition to superior and middle frontal gyri, orbital gyrus and fusiform gyrus, also relate in structure and function to the degree of perceived parental care that mothers themselves experienced as children. Regions of this wide neural network support social cognition/mentalisation/empathy in healthy mothers but are hyporesponsive to infant stimuli in mothers with insecure attachment and substance use disorders. This broad domain shows potential as a marker of impaired maternal caregiving that might benefit from greater specificity and standardisation in the future. Detecting neural endophenotypes of disrupted maternal care may allow for earlier inventions and improve the mental and physical health of mother and offspring.

\section{Default mode network}

An increasingly popular approach in neuroscience has been to examine the intrinsic functional organisation of brain through examination of spontaneous low frequency BOLD activity when individuals are at rest with eyes closed or attending to a fixation cross. Reviews of this technology $(73,130)$ emphasise that neural processes that occur over minutes (rather than seconds) and utilise significant body energetics (20\% of body energy used for ongoing neural activity compared to 5\% for task-specific activity) might have greater validity for the study of behaviour. The default mode network (DMN) has emerged as a key network of interest that is more active during passive than active cognitive tasks in meta-analytic resting state positron emission tomography $(131,132)$ and fMRI studies $(133,134)$. Key regions of the DMN include the PCC, ACC, inferior parietal cortex and precuneus.

Functional MRI studies comparing spontaneous/internal cognition to external attention and monitoring may be important for a range of psychopathology (135), including parent-child relational problems and $\mathrm{FMRI}$ studies designed to specifically elicit self-referent ideation $(136,137)$. In depressive and anxiety disorders, the DMN is considered to subserve non-adaptive, ruminative, self-referential ideation based upon varied reports of altered PCC connectivity to limbic regions in MDD $(138,139)$, greater cross-network (salience and executive networks) associations with the DMN via the dorsal nexus (140) and increased hippocampal-driven ventral ACC activity (141), amongst others. In several studies, the degree of network connectivity within the DMN was associated with the duration of current depressive episode (138) or rumination severity (142). The study by Johnson et al. (136) on subtypes of self-relevant thought noted the anteroinferior PCC had a more outward, preventative focus on duties and responsibilities and the ventromedial ACC had a more inward, promotional focus on self-related hopes and aspirations. A subsequent study (143) of functional DMN regions during specified tasks of referential ideation found that individuals with
MDD had less anterior mPFC activity to the self-evaluative condition and less disengagement/deactivation during a distraction task.

Three published resting BOLD papers have begun to examine DMN activity in PPD. In a study of 14 women with MDD versus 23 healthy women approximately 10 weeks postpartum, Chase et al. (144) selected the PCC as a seed region from which to examine DMN connectivity with whole brain activity during rest because the PCC is a core DMN region involved in self-reflection and social cognition (145), as well as being associated with thinking about duties and responsibilities to others (136). They found that the PCC and right amygdala were negatively coupled in depressed compared to healthy mothers, suggesting that PPD might involve the disruption of outward, preventative aspects of self-relevant thought and perhaps empathy. A second study by Deligiannidis et al. (146) of eight PPD and nine healthy mothers studied at 9 weeks postpartum similarly showed attenuated functional connectivity in numerous corticolimbic circuits, including coupling within the DMN of ACC, inferior parietal cortex and precuneus, as well as between DMN nodes and amygdala. A contradictory report by Xiao-juan et al. (147) revealed heightened PCC connectivity in PPD, using nearest neighbour, regional homogeneity methodology. Additional research related to the content of maternal thought during the resting phase, as well as paradigms that constrain types of self-relevant thought, alongside mother-infant interactional data, will be important to clarify the relationship between rumination, self-reflection, maternal depression and caregiving.

\section{Summary point}

More work remains to be carried out in the field of intrinsic neural activity in new mothers, although there are preliminary findings of circuitry disconnectivity that might relate to impaired empathic and self-other-relational processing in PPD. Additional correlative studies are needed.

\section{Integrative concepts which transcend a neural network approach}

Although it is convenient to divide neural networks into the four domains above for the purpose of a selective literature review, it is evident that there is significant overlap and interactive effects among these neural networks, just as there are interactive/overlapping themes in the approach to maternal psychopathology and maternal caregiving. Indeed, a developmental perspective of maternal socioemotional neuroscience would suggest that early experience and presence of adversity interacts with current life circumstances to create neural vulnerability or resilience during motherhood. In this vein, what we define as maternal depression or poor caregiving might similarly derive from the neural imprint of adverse early experience. Adverse early-life experiences that impact upon an individual's attachment to a primary caregiver are of particular interest because convergent research has demonstrated that an individual's attachment style is a central dimension contributing to the onset of and recovery from affective symptoms (148-150), as well as maternal caregiving $(151,152)$. In addition, current 
healthy social attachments, which are more likely if the attachment capacity is established at a young age, modulate emotional response to threat and loss, as originally articulated by Bowlby (117), who described that the prototypical response to separation from an attachment figure involves 'protest' or anxiety followed by 'despair' or depression. However, he noted that individuals with enduring attachments to others may experience anxiety without depression. Because the prevailing context for postpartum affective disorders is a new affiliative relationship between mother and infant accompanied by dramatic changes in pre-existing relationships between the mother and her social network, new motherhood is an ideal 'laboratory' in which to test the role of attachment in modulating multiple interacting neural system responses.

Indeed, parental brain findings have been interpreted with respect to maternal attachment behaviours, which themselves affect the development of such circuits in the infant $(153,154)$ and may also be important to more generalised forms of caregiving (155). From the infant attachment perspective, Laurent and Ablow (156) demonstrated higher activity in the amygdala, parahippocampus, and right posterior insula for mothers responding to their own baby-cry versus non-cry control sounds according to decreasing attachment security of their infants. This is in keeping with findings indicating that intrusive and forceful maternal behaviour, as assessed in infant-mother interaction, was related to greater maternal activation in the amygdala when viewing their infant in solitary play and when viewing videos of themselves interacting with their infants (125). Intrusive maternal behaviour was also related to increased insula and temporal pole activation (auditory processing) when listening to cry sounds of their own versus unfamiliar infants (157). This work on parents neatly reinforces earlier work raising the amygdala as a key node in mediating the effects of attachment insecurity (158). Conversely, in a mixed group of breastfeeding and formula-feeding mothers, Kim et al. (48) found that greater cry-related right amygdala and SFG activity at 24 weeks postpartum was related to greater maternal sensitivity to their infants at 3-4 months postpartum. This area of investigation will benefit from increased sample sizes and $\mathrm{fMRI}$ paradigm refinement, with the ultimate goal of establishing neural risk markers for maternal caregiving. Inroads into such improvements are seen in the recent work of Wan et al. (159), in which brain responses to visual baby stimuli in a group of 20 mothers was correlated with the quality of her concurrent parental behaviour and with her perceptions of infant warmth.

The neurobiology of maternal affective health and empathy should continue to be informed by the broader literature on mood disorders, in which developmental effects of environment are programmed from infancy (160) through adulthood, most notably through the HPA axis with the important involvement of amygdala, hippocampus and PFC (161). The negative impact of adversity, poor attachment, exposure to stress hormones on neural systems for emotion regulation and self-other relational processing is wellknown. Numerous retrospective studies report correlations between own experience of negative or rejecting parenting and adult depression (162), including PPD (163). Although brain imaging research is underway with low socioeconomic status parents, we can begin considering brain-based deficits in emotion response and regulation from the chronic childhood experience of poverty as possibly injurious to parenting behaviours (164). We thus expect future studies to confirm differences already reported from adverse early-life experiences (120), and elaborate the importance of specific forms of adversity on parenting dysfunctions toward better targeted and effective treatments.

It is important to also consider the potential for neuroplasticity inherent in the perinatal period both via the surge of hormonerelated brain changes, particularly in the hippocampus and amygdala $(165,166)$ and a richness of environmental support and maternal motivation for change that can accompany the perinatal period. In theory, and perhaps for some women, with the proper environmental support, the neural trajectory can be optimised leading to healthy mood and good social relationships in the puerperium. As described previously and also reported by Lonstein et al. (167), studies of postpartum rodents have demonstrated that pulsatile secretion of oxytocin and prolactin during delivery and lactation are associated with diminished fear responses (30) and increases in mesiostriatal dopaminergic reward system function (168), which may help set the stage for resiliency. Animal studies suggest that structural changes occur in the maternal brain during the early postpartum period in regions such as the hypothalamus, amygdala, parietal lobe and PFC, and such changes are related to the expression of maternal behaviours. In an attempt to explore structural plasticity in new parent brains, Kim et al. (53) conducted a voxelbased morphometry study of mothers' brains at 2-4 weeks postpartum which was repeated at 3-4 months postpartum. Findings revealed that the gray matter volume increases in the PFC, parietal lobes and midbrain areas over time. Increased gray matter volume in the midbrain, including the hypothalamus, substantia nigra and amygdala, was associated with maternal positive perception of her baby. These results suggest that the first months of motherhood in humans are accompanied by structural changes in brain regions implicated in maternal motivation and behaviours.

\section{Genetics}

Advances in molecular biology have highlighted the role of epigenetic mechanisms in regulating gene activity, neurobiology and behaviour, as well as the potential role of environmentally-induced epigenetic variation in linking early-life exposures to long-term biobehavioural outcomes, including parenting behaviours. Maternal perinatal distress may be associated with both foetal and infant developmental trajectories through epigenetic mechanisms. Later, postpartum experiences may have a critical moderating influence on antenatal effects, the antenatal-postpartum interplay, and the developmental and epigenetic consequences of postpartum mother-infant interactions. The in utero environment is regulated by placental function and there is emerging evidence that the placenta is highly susceptible to maternal distress and a target of epigenetic dysregulation. Of note, recent studies also demonstrate epigenetic paternal (father) effects (169), including the transmission of stress-induced pathologies such as depression $(170,171)$. Integrating studies of antenatal exposures, placental function and 
postpartum maternal care with the exploration of epigenetic mechanisms may provide novel insights into the pathophysiology induced by maternal distress.

In human and other mammalian mothers, research suggests that early quality of care in the family of origin may affect subsequent parenting (172-175), with clear associations between the maternal history of abuse and child maltreatment. Approximately 30\% of mothers who were abused as children go on to abuse their own children, compared to 5\% in mothers not reporting abuse (176). Although the biological mechanisms underlying a posited 'cycle of abuse' are not well understood, there is support for the intergenerational transmission of parenting styles, bonding, attachment and maternal rejection (177-182). Furthermore, epidemiological studies indicate that children exposed to early adverse experiences, including those related to bonding and attachment, are at increased risk for the development of depression, anxiety and other stress-related disorders in adolescence (183-185) and adulthood (186-188). Protective factors for prospective mothers from the riskiness of their early experiences include social supports in the environment of the developing child (189-193), as well a partner relationship with a supportive spouse in adulthood (194). Thus, the effects of earlyexperience on the developing brain promise to provide mechanisms for understanding and improving next generations' capacity for sensitive parental behaviours $(118,120,195)$ with resulting implications for public policy (196).

Although epigenetics may shed light on environmental contributions to PPD, genetic factors under gene mapping research may also help identify differential vulnerability to the changes in gonadal steroid levels that occur at delivery. A genetic study compared nine women with PPD and ten postpartum nondepressed women (197). Gene expression profiles correctly classified $84 \%$ of patients as depressed or nondepressed, and gene expression was correlated with the severity of depressive symptoms and clinical course of illness. Moreover, the women with PPD showed a global reduction of gene transcription after delivery and differential immune activation, as well as decreased transcriptional activation, cell proliferation, nucleotide binding, and DNA replication and repair. One large-scale genome-wide association study $(n=1210)$ examined genetic influences on postpartum depressive symptoms and showed modest evidence of an association between postpartum mood symptoms and a single-nucleotide polymorphism on chromosome 1 in the hemicentin gene HMCN1 (198) that encodes a member of the immunoglobulin superfamily. HMCN1 contains four oestrogen-binding sites and may contribute a phenotype characterised by mood destabilisation in the context of normal changes in gonadal steroid levels at delivery. If such genes have biologically relevant products, they may ultimately guide earlier diagnostic and more specific treatment approaches.

\section{Nosological issues in psychopathology occurring in the puerperium}

Because of the profound physiological changes that characterise pregnancy and childbirth (notably the dramatic changes in steroid hormone levels and the perturbations in mood, appetite, energy and sleep associated with childbirth and infant care), it has been suggested that PPD may be distinct from depression that occurs at other times (199). In one study, PPD increased the risk of future PPD but not for depressive episodes that occurred outside of the postpartum period (200). In addition, women whose PPD represented a recurrent depression were at increased risk for depressive episodes occurring outside of the postpartum period but not in the postpartum period. Also, Altemus et al. (201) distinguished between antenatal versus postpartum onset MDD, with the latter being more commonly associated with obsessions and compulsions and the former being come commonly associated with psychosocial stress and nonperinatal MDD.

Notably, a few studies link caesarean section with an increased risk for PPD (202) and PPD is associated with breastfeeding difficulties (203); thus, the role of neuroendocrine perturbations underlying the onset of PPD remain to be examined (204). Additional insights may be gained by considering postpartum psychopathology in the context of birth-related factors, including birthing method (e.g. vaginal, caesarian section), birthing complications, feeding difficulties, sleep patterns, libido, partner intimacy and ongoing medical conditions, such as urinary incontinence and hyperglycaemia.

Hormone withdrawal theories suggest that the withdrawal of oestradiol and progesterone may be a causative link in the chain of events before postpartum blues and depression in some vulnerable women $(205,206)$. In addition, cortisol may be particularly dysregulated in PPD (207). These findings are consistent with depression models that implicate dysregulation of stress hormones, particularly cortisol (208). Indeed, several recent reviews converge on a significant role for dysregulation of the HPA axis in the development of depression in postpartum women $(206,209)$. More work is required to confirm the involvement of gonadal steroids in PPD $(207,210-$ 212). Perhaps neuroimaging can help integrate hormone and brain systems in the aetiology and possible treatments of depression by modulating the HPA axis or oestradiol (213-215). As a first step, Ho et al. (216) reported on the connection between cortisol regulation and maternal ventral ACC activity in the discrimination between positive and negative social signals from own-infants in a social decision-making task. Such neurohormonal integration may be disrupted in psychopathology and interfere with normal maternal decision-making in the care for their infant.

\section{Summary}

These emerging findings point to the potential capacity of $\mathrm{fMRI}$ paradigms that activate the salience/fear circuitry, the maternal reward/ attachment network, and systems supporting self-relevant thought to yield critical information for understanding PPD and maternal caregiving. Convergence of findings of hypoactivity and cortico-limbic disengagement to emotional, infant and reward cues in mothers with PPD provides a foundation for, and also offers promise for, defining neural biomarkers to estimate PPD risk, as well as guide treatment selection. Personalisation of treatment is needed to increase treatment remission above the currently disappointing rates of $30-50 \%(217)$, as well as to decrease the expense of ineffective treatment and decrease the family burden of postpartum mental 


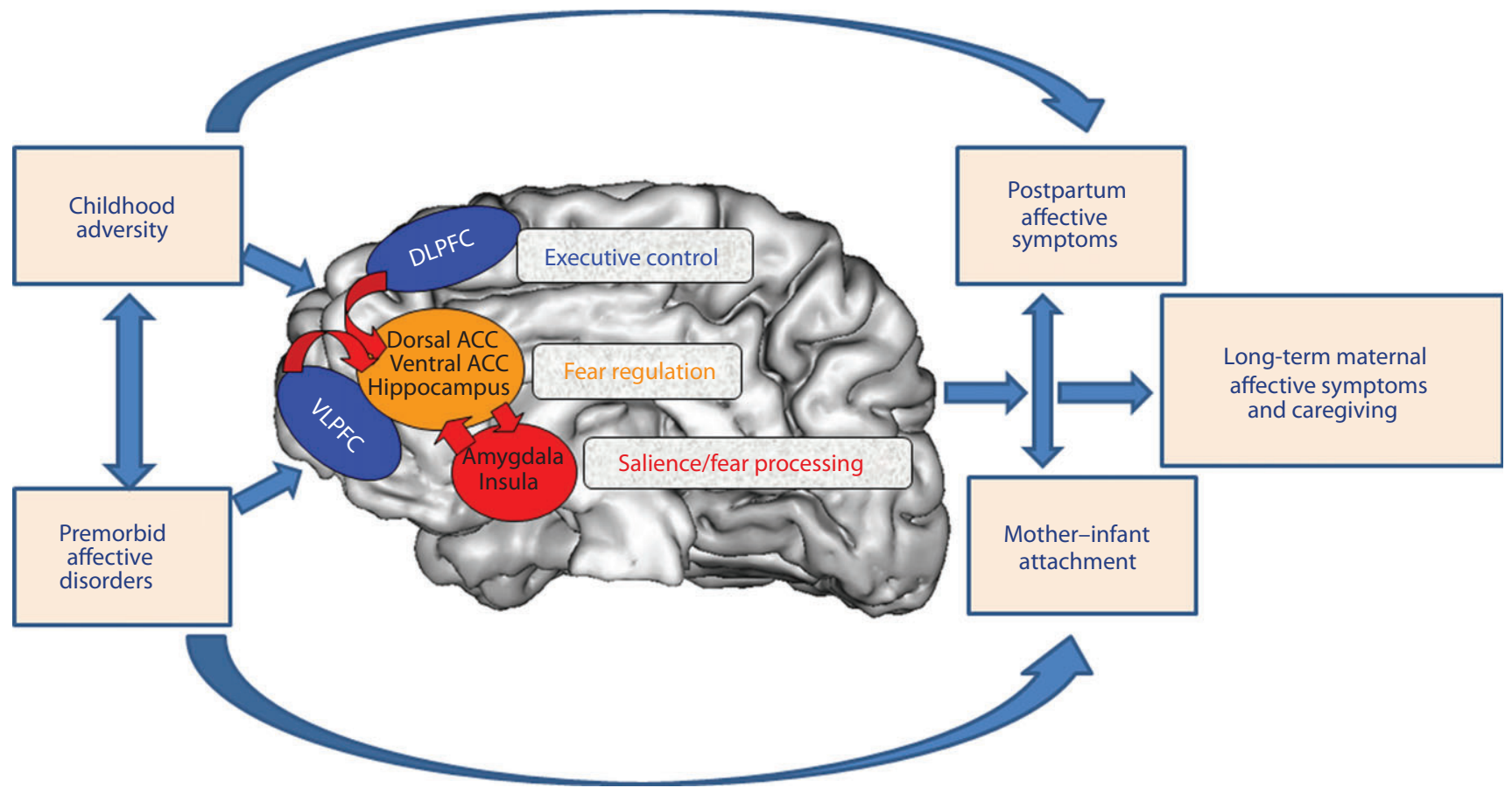

Fig. 1. Putative model of relationships between multiple early-life factors, representative brain circuits of interest, and maternal affective and caregiving outcomes (note the following network-brain region groupings: executive control [dorsolateral prefrontal cortex (DLPFC), ventrolateral prefrontal cortex (VLPFC)], fear regulation [dorsal anterior cingulate cortex (ACC), ventral anterior cingulate cortex, hippocampus], and salience/fear processing [amygdala, insula]). Note also that pertinent circuitries are not shown (i.e. reward and attachment) and that other biological mechanisms, specifically genetic, are also left out for the sake of simplicity. An aim of ongoing research in maternal affective neuroscience is to examine complex models of maternal psychopathology and parenting in large maternal samples to identify neural, behavioural, and psychosocial predictors of postpartum affective disorders and maternal caregiving behaviours. Application of such predictors to mothers prior to pregnancy or perinatally shows promise with respect to the design of improved treatments and for applying early interventions to improve outcomes for mothers and children. Adapted from Phillips et al. (222).

illness. Neuroimaging is increasingly becoming widespread and feasible to implement. For example, a robust fMRI paradigm of $10 \mathrm{~min}$ in duration could cost in the vicinity of $\$ 500$ for acquisition and analysis. Therefore, it is within the realm of possibility that risk assessment or treatment predicting fMRI could have a place in clinical practice once a set of neuroimaging paradigms is honed based on further study in larger samples. Further decreases in costs are anticipated as a result of advancements in technology.

In Fig. 1, we depict a putative model of relationships between multiple early-life factors, representative brain circuits of interest, and maternal affective and caregiving outcomes. One aim of ongoing research in maternal affective neuroscience is to examine complex models of maternal psychopathology and parenting in large maternal samples to identify neural, behavioural and psychosocial predictors of postpartum affective disorders and maternal caregiving behaviours. The application of such predictors to mothers prior to pregnancy or perinatally also holds promise with respect to designing improved treatments and applying early interventions that improve outcomes for mothers and children.

\section{Future directions}

We conclude by identifying several areas that are ripe for further investigation and stand to greatly enhance our understanding of postpartum affective disturbance.
1 An under-studied area is how early postpartum hormonal fluctuations modulate neural circuits to result in clinical symptoms. For example, Sacher et al. (218) have demonstrated the value of such work by their findings of greater monoamine catabolism in the early puerperium compared to nonchildbearing time points. Knowing which neural changes are normative versus pathological in the early puerperium could help to define more effective treatments, as well as select the group of women in greatest need of preventive care. Designs using hormonal manipulation, abortion or adoption may be useful in this endeavour.

2 Ongoing neuroimaging studies would benefit from the implementation of functional and structural connectivity, as well as machine learning analyses, to foster greater understanding of aberrant neural circuits $(92,219)$. Functional MRI paradigms that can tap into standard concepts in the emotion literature can yield useful information about maternal psychopathology, whereas ecologically relevant infant stimuli are necessary to parse the circuitry of maternal caregiving. An important additional goal will be to examine how the different neural circuitries are integrated and whether there is a temporal evolution after childbirth in the predominance of one circuitry over another. For example, a hyperactive salience and fear network may temporally precede a hypoactive reward circuitry, although functional relationships between these two circuitries may not be linear. These questions will benefit greatly from future research. 
3 Subject samples must clearly grow in size and should be selected in a way that hypotheses regarding mood, attachment, parenting quality and sociodemographic context (i.e. paternal, sibling, violence factors) can be studied in concert. For example, a sample size of 120 women and 10 covariates provides $>80 \%$ power to detect an $R^{2}$ of 0.15 (small-medium effect size) with $P=0.05$ (220). In addition, dimensions of psychopathology are expected to have greater relevance to the neural mechanisms captured with $\mathrm{fMRI}$ paradigms compared to dichotomous diagnoses. As such, efforts to define basic functioning dimensions underlying traditionally defined disorders have high value for establishing brain-behaviour relationships, as suggested by the Research Domain Criteria (RDoC) project set forth by the National Institutes of Mental Health (NIMH) (221).

4 A recurrent question asked of researchers in this field is the comparability or distinction between PPD and nonpostpartum depression. A well-constructed approach with respect to defining areas of similarity and divergence is needed to clarify the extent to which postpartum affective neuroscience is generalisable to the greater population and vice versa. Furthermore, the effects of parity, multiparity, duration post-delivery and other factors must be closely examined.

5 As we learn more about maternal psychopathology and parenting, developing standardised fMRI protocols (65) that can isolate the robustness of deficits across overlapping networks will represent an important approach. It might be that futurejne studies will explore graded stimuli, decision-making tasks or responses to more sophisticated and personally tailored aspects of parenting, rather than simply own versus other types of contrast to reveal the important nuances of parent-infant relationships

6 Integrated studies of neuroimaging and treatment are critically needed to identify which neural circuitry activation and connectivity patterns are linked with the treatment response overall, as well as unique behavioural and pharmacologic treatment modalities.

\section{Acknowledgements}

The work was supported by grants HD067185 (EMK, MLP, AEH) and the National Alliance for Research on Schizophrenia and Depression/Brain and Behavior Foundation, Klingenstein Third Generation Foundation, NIMHD/ NICHD RC2MD004767-01, the Michigan Institute for Clinical Health Research and the National Center for Advancing Translational Sciences, UL1TR000433, Robert Wood Johnson Health and Society Scholar Award, the University of Michigan Injury Center (JES), and AACAP-NIDA K12 DA000357 (MSH, Physician Scientist Program). The authors declare that there are no conflicts of interest.

Received 15 January 2014,

revised 18 July 2014,

accepted 21 July 2014

\section{References}

1 Swain JE, Lorberbaum JP, Kose S, Strathearn L. Brain basis of early parent-infant interactions: psychology, physiology, and in vivo functional neuroimaging studies. J Child Psychol Psychiatry 2007; 48: 262-287.
2 Seeley WW, Menon V, Schatzberg AF, Keller J, Glover GH, Kenna $H_{1}$ Reiss AL, Greicius MD. Dissociable intrinsic connectivity networks for salience processing and executive control. J Neurosci 2007; 27: 23492356.

3 Etkin A, Wager TD. Functional neuroimaging of anxiety: a meta-analysis of emotional processing in PTSD, social anxiety disorder, and specific phobia. Am J Psychiatry 2007; 164: 1476-1488.

4 Milad MR, Quirk GJ, Pitman RK, Orr SP, Fischl B, Rauch SL. A role for the human dorsal anterior cingulate cortex in fear expression. Biol Psychiatry 2007; 62: 1191-1194.

5 Somerville LH, Whalen PJ, Kelley WM. Human bed nucleus of the stria terminalis indexes hypervigilant threat monitoring. Biol Psychiatry 2010; 68: 416-424.

6 Critchley HD, Wiens S, Rotshtein P, Ohman A, Dolan RJ. Neural systems supporting interoceptive awareness. Nat Neurosci 2004; 7: 189195.

7 Paulus MP, Stein MB. An Insular View of Anxiety. Biol Psychiatry 2006; 60: 383-387.

8 Davis M, Walker DL, Miles L, Grillon C. Phasic vs sustained fear in rats and humans: role of the extended amygdala in fear vs anxiety. Neuropsychopharmacology 2010; 35: 105-135.

9 LeDoux JE. Clues from the brain. Ann Rev Psychol 1995; 46: 209-235.

10 Disner SG, Beevers CG, Haigh EA, Beck AT. Neural mechanisms of the cognitive model of depression. Nat Rev Neurosci 2011; 12: 467-477.

11 Anand A, Li Y, Wang Y, Gardner K, Lowe MJ Reciprocal effects of antidepressant treatment on activity and connectivity of the mood regulating circuit. J Neuropsychiatry Clin Neurosci 2007; 19: 274-282.

12 Dannlowski U, Ohrmann P, Bauer J, Kugel H, Arolt V, Heindel W, Kersting A, Baune BT, Suslow T. Amygdala reactivity to masked negative faces is associated with automatic judgmental bias in major depression: a 3 T fMRI study. J Psychiatry Neurosci 2007; 32: 423-429.

13 Fales CL, Barch DM, Rundle MM, Mintun MA, Snyder AZ, Cohen JD, Mathews J, Sheline Yl. Altered emotional interference processing in affective and cognitive-control brain circuitry in major depression. Biol Psychiatry 2008; 63: 377-384.

$14 \mathrm{Fu}$ CH, Williams SC, Cleare AJ, Brammer MJ, Walsh ND, Kim J, Andrew $\mathrm{CM}$, Pich EM, Williams PM, Reed $\sqcup$. Attenuation of the neural response to sad faces in major depressionby antidepressant treatment: a prospective, event-related functional magnetic resonance imagingstudy. Arch Gen Psychiatry 2004; 61: 877-889.

15 Fu CH, Williams SC, Brammer MJ, Suckling J, Kim J, Cleare AJ, Walsh ND, Mitterschiffthaler MT, Andrew CM, Pich EM, Bullmore ET. Neural responses to happy facial expressions in major depression following antidepressant treatment.[see comment]. Am J Psychiatry 2007; 164: 599-607.

16 Neumeister A, Drevets WC, Belfer I, Luckenbaugh DA, Henry S, Bonne O, Herscovitch P, Goldman D, Charney DS. Effects of a alpha $2 \mathrm{C}$-adrenoreceptor gene polymorphism on neural responses to facial expressions in depression. Neuropsychopharmacology 2006; 31: 1550-1556.

17 Sheline $\mathrm{Y}$, Barch DM, Donnelly JM, Ollinger JM, Snyder AZ, Mintun MA. Increased amygdala response to masked emotional faces in depressed subjects resolves with antidepressant treatment: an fMRI study. Biol Psychiatry 2001; 50: 651-658.

18 Surguladze SA, Brammer MJ, Young AW, Keedwell P, Travis MJ, Williams S, Phillips ML. A differential pattern of neural response towards sad versus happy facial facial expressions in Major Depressive Disorder. Biol Psychiatry 2005; 57: 201-209.

19 Siegle GJ, Steinhauer SR, Thase ME, Stenger VA, Carter CS. Can't shake that feeling: $\mathrm{fMRI}$ assessment of sustained amygdala activity in response to emotional information in depressed individuals. Biol Psychiatry 2002; 51: 693-707. 
20 Phillips ML, Drevets WC, Rauch SL, Lane R. Neurobiology of emotion perception II: implications for major psychiatric disorders. Biol Psychiatry 2003; 54: 515-528.

21 Neumeister A, Drevets WC, Belfer I, Luckenbaugh DA, Henry S, Bonne O, Herscovitch P, Goldman D, Charney DS. Effects of a alpha $2 \mathrm{C}$-adrenoreceptor gene polymorphism on neural responses to facial expressions in depression. Neuropsychopharmacology 2006; 31: 1750-1756.

22 Victor TA, Furey ML, Fromm SJ, Ohman A, Drevets WC. Relationship between amygdala responses to masked faces and mood state and treatment in major depressive disorder. Arch Gen Psychiatry 2010; 67: 1128-1138.

23 Pulcu E, Lythe K, Elliott R, Green S, Moll J, Deakin JF, Zahn R. Increased amygdala response to shame in remitted major depressive disorder. PLOS ONE 2014; 9: e86900.

24 Arnone D, McKie S, Elliott R, Thomas EJ, Downey D, Juhasz G, Williams SR, Deakin JFW, Anderson IM. Increased amygdala responses to sad but not fearful faces in major depression: relation to mood state and pharmacological treatment. Am J Psychiatry 2012; 169: 841-850.

25 Norbury R, Selvaraj S, Taylor M, Harmer C, Cowen P. Increased neural response to fear in patients recovered from depression: a $3 T$ functional magnetic resonance imaging study. Psychol Med 2010; 40: 425.

26 Etkin A, Prater KE, Schatzberg AF, Menon V, Greicius MD. Disrupted amygdalar subregion functional connectivity and evidence of a compensatory network in generalized anxiety disorder. Arch Gen Psychiatry 2009; 66: 1361-1372.

27 Etkin A, Schatzberg AF. Common abnormalities and disorder-specific compensation during implicit regulation of emotional processing in generalized anxiety and major depressive disorders. Am J Psychiatry 2011; 168: 968-978.

28 Robinson OJ, Charney DR, Overstreet C, Vytal K, Grillon C. The adaptive threat bias in anxiety: amygdala-dorsomedial prefrontal cortex coupling and aversive amplification. Neurolmage 2012; 60: 523-529.

29 Wartella J, Amory E, Lomas LM, Macbeth A, McNamara I, Stevens L, Lambert $K G$, Kinsley $\mathrm{CH}$. Single or multiple reproductive experiences attenuate neurobehavioral stress and fear responses in the female rat. Physiol Behav 2003; 79: 373-381.

30 Neumann ID. Brain mechanisms underlying emotionalalterations in the peripartum period in rats. Depress Anxiety 2003; 17: 111-121.

31 Torner L, Neumann ID. The brain prolactin system: involvement in stress response adaptations in lactation. Stress 2002; 5: 249-257.

32 Bosch OJ, Meddle SL, Beiderbeck DI, Douglas AJ, Neumann ID. Brain oxytocin correlates with maternal aggression: link to anxiety. J Neurosci 2005; 25: 6807-6815.

33 Febo M, Shields J, Ferris CF, King JA. Oxytocin modulates unconditioned fear response in lactating dams: an fMRI study. Brain Res 2009; 1302: 183-193.

34 Caffrey MK, Nephew BC, Febo M. Central vasopressin V1a receptors modulate neural processing in mothers facing intruder threat to pups. Neuropharmacology 2010; 58: 107-116.

35 Hillerer KM, Neumann ID, Slattery DA. From stress to postpartum mood and anxiety disorders: how chronic peripartum stress can impair maternal adaptations. Neuroendocrinology 2011; 95: 22-38.

36 Ferris CF, Stolberg $T$, Kulkarni $P$, Murugavel $M$, Blanchard $R$, Blanchard DC, Febo M, Brevard M, Simon NG. Imaging the neural circuitry and chemical control of aggressive motivation. BMC Neurosci 2008; 9: 111.

37 Noriuchi M, Kikuchi $Y$, Senoo A. The functional neuroanatomy of maternal love: mother's response to infant's attachment behaviors. Biol Psychiatry 2008; 63: 415-423.

38 Strathearn L, Li J, Fonagy P, Montague PR What's in a smile? maternal brain responses to infant facial cues. Pediatrics 2008; 122: 40-51.
39 Barrett J, Wonch KE, Gonzalez A, Ali N, Steiner M, Hall GB, Fleming AS. Maternal affect and quality of parenting experiences are related to amygdala response to infant faces. Soc Neurosci 2011; 252-268.

40 Seifritz E, Esposito F, Neuhoff JG, Luthi A, Mustovic H, Dammann G, von Bardeleben U, Radue EW, Cirillo S, Tedeschi G, Di Salle F. Differential sex-independent amygdala response to infant crying and laughing in parents versus nonparents. Biol Psychiatry 2003; 54: 1367-1375.

41 Lorberbaum JP, Newman JD, Horwitz AR, Dubno JR, Lydiard RB, Hammer MB, Bohning DE, George MS. A potential role for thalamocingulate circuitry in human maternal behavior. Biol Psychiatry 2002; 51: 431445.

42 Swain JE, Tasgin E, Mayes LC, Feldman R, Constable RT, Leckman JF. Maternal brain response to own baby-cry is affected by cesarean section delivery. J Child Psychol Psychiatry 2008; 49: 1042-1052.

43 Laurent HK, Ablow JC. A cry in the dark: depressed mothers show reduced neural activation to their own infant's cry. Soc Cogn Affect Neurosci 2012; 7: 125-134.

44 Leibenluft E, Gobbini MI, Harrison T, Haxby JV. Mothers' neural activation in reponse to pictures of their children and other children. Biol Psychiatry 2004; 56: 225-232.

45 Bartels A, Zeki S. The neural correlates of maternal and romantic love. Neuroimage 2004; 21: 155-1166.

46 Strathearn L, Fonagy P, Amico J, Montague PR. Adult attachment predicts maternal brain and oxytocin response to infant cues. Neuropsychopharmacology 2009; 34: 2655-2666.

47 Swain J, Ho S, Rosenblum K, Finegood E, Richardson P, Dayton C, Akce L, Marcus S, Phan K, Muzik M. Maternal brain responses to baby stimuli are modulated by mood disorders. Paper Presented at: Biological Psychiatry 2012.

48 Kim P, Feldman R, Mayes LC, Eicher V, Thompson N, Leckman JF, Swain JE. Breastfeeding, brain activation to own infant cry, and maternal sensitivity. J Child Psychol Psychiatry 2011; 52: 907-915.

49 Silverman ME, Loudon H, Safier M, Protopopescu X, Leiter G, Liu X, Goldstein M. Neural dysfunction in postpartum depression: an fMRI pilot study. CNS Spectr 2007; 12: 853-862.

50 Moses-Kolko EL, Perlman SB, Wisner KL, James J, Saul AT, Phillips ML. Abnormally reduced dorsomedial prefrontal cortical activity and effective connectivity with amygdala in response to negative emotional faces in postpartum depression. Am J Psychiatry 2010; 167: 13731380.

51 Swain JE, Lorberbaum JP. Imaging the human parental brain. Neurobiology of the parental brain. 2008; 83-100.

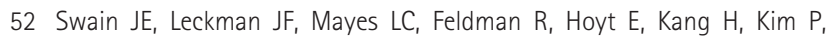
David D, Nguyen S, Constable RT, Schultz RT. Functional brain activations of parents listening to their own baby-cry change over the early postpartum. Dev Psychobiol 2014; under review.

53 Kim P, Leckman JF, Mayes LC, Feldman R, Wang X, Swain JE. The plasticity of human maternal brain: longitudinal changes in brain anatomy during the early postpartum period. Behav Neurosci 2010; 124: 695700.

54 Kinsley $\mathrm{CH}$, Meyer EA. The construction of the maternal brain: theoretical comment on Kim et al. (2010). Behav Neurosci 2010; 124: 710714.

55 Hopper JW, Frewen PA, van der Kolk BA, Lanius RA. Neural correlates of reexperiencing, avoidance, and dissociation in PTSD: Symptom dimensions and emotion dysregulation in responses to script-driven trauma imagery. J Trauma Stress 2007; 20: 713-725.

56 Herringa RJ, Phillips ML, Fournier JC, Kronhaus DM, Germain A. Childhood and adult trauma both correlate with dorsal anterior cingulate activation to threat in combat veterans. Psychol Med 2013; 43: 15331542. 
57 Lanius RA, Vermetten E, Loewenstein RJ, Brand B, Schmahl C, Bremner JD, Spiegel D. Emotion modulation in PTSD: clinical and neurobiological evidence for a dissociative subtype. Am J Psychiatry 2010; 167: 640647.

58 Meewisse ML, Reitsma JB, de Vries GJ, Gersons BP, Olff M. Cortisol and post-traumatic stress disorder in adults: systematic review and metaanalysis. Br J Psychiatry 2007; 191: 387-392.

59 Shea $A$, Walsh $C$, Macmillan $H$, Steiner M. Child maltreatment and HPA axis dysregulation: relationship to major depressive disorder and post traumatic stress disorder in females. Psychoneuroendocrinology 2005; 30: 162-178.

60 Morris MC, Compas BE, Garber J. Relations among posttraumatic stress disorder, comorbid major depression, and HPA function: a systematic review and meta-analysis. Clin Psychol Rev 2012; 32: 301-315.

61 Schechter DS, Moser DA, Wang Z, Marsh R, Hao X, Duan Y, Yu S, Gunter B, Murphy D, McCaw J, Kangarlu A, Willheim E, Myers MM, Hofer MA, Peterson BS. An fMRI study of the brain responses of traumatized mothers to viewing their toddlers during separation and play. Soc Cogn Affect Neurosci 2012; 7: 969-979.

62 Schechter DS, Willheim E, Hinojosa C, Scholfield-Kleinman K, Turner JB,

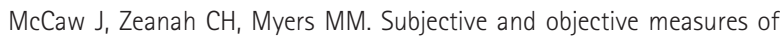
parent-child relationship dysfunction, child separation distress, and joint attention. Psychiatry 2010; 73: 130-144.

63 Moser DA, Aue T, Wang Z, Rusconi SS, Favez N, Peterson BS, Schechter DS. Limbic brain responses in mothers with post-traumatic stress disorder and comorbid dissociation to video clips of their children. Stress 2013; 16: 493-502.

64 Lanius RA, Frewen PA, Girotti M, Neufeld RWJ, Stevens TK, Densmore M. Neural correlates of trauma script-imagery in posttraumatic stress disorder with and without comorbid major depression: a functional MRI investigation. Psychiatry Res 2007; 155: 45-56.

65 Korgaonkar MS, Grieve SM, Etkin A, Koslow SH, Williams LM. Using standardized fMRI protocols to identify patterns of prefrontal circuit dysregulation that are common and specific to cognitive and emotional tasks in major depressive disorder: first wave results from the iSPOT-D study. Neuropsychopharmacology 2013; 38: 863-871.

66 Harvey P-O, Fossati P, Pochon J-B, Levy R, LeBastard G, Lehéricy S, Allilaire $J-F$, Dubois B. Cognitive control and brain resources in major depression: an fMRI study using the n-back task. Neurolmage 2005; 26: 860-869.

67 Liotti M, Mayberg HS, McGinnis S, Brannan SL, Jerabek P. Unmasking disease -specific cerebral blood flow abnormalities: mood challenge in patients with remitted unipolar depression. Am J Psychatry 2002; 159: 1830-1840.

68 Elliott R, Baker SC, Rogers RD, O'Leary DA, Paykel ES, Frith CD, Dolan RJ, Sahakian BJ. Prefrontal dysfunction in depressed patients performing a complex planning task: a study using positron emission tomography. Psychol Med 1997; 27: 931-942.

69 Goethals I, Audenaert K, Jacobs F, Van de Wiele C, Ham H, Pyck H, Vandierendonck $A$, Van Heeringen $C$, Dierckx R. Blunted prefrontal perfusion in depressed patients performing the Tower of London task. Psychiatry Res 2005; 139: 31-40.

70 Okada G, Okamoto Y, Morinobu S, Yamawaki S, Yokota N. Attenuated left prefrontal activation during a verbal fluency task in patients with depression. Neuropsychopharmacology 2003; 47: 21-26.

71 Versace A, Thompson WK, Zhou D, Almeida JR, Hassel S, Klein CR, Kupfer DJ, Phillips ML. Abnormal left and right amygdala-orbitofrontal cortical functional connectivity to emotional faces: state versus trait vulnerability markers of depression in bipolar disorder. Biol Psychiatry 2010; 67: 422-431.

72 Almeida JR, Versace A, Mechelli A, Hassel S, Quevedo K, Kupfer DJ, Phillips ML. Abnormal amygdala-prefrontal effective connectivity to happy faces differentiates bipolar from major depression. Biol Psychiatry 2009; 66: 451-459.

73 Hamilton JP, Chen MC, Gotlib IH. Neural systems approaches to understanding major depressive disorder: an intrinsic functional organization perspective. Neurobiol Dis 2013; 52: 4-11.

74 de Groot RH, Vuurman EF, Hornstra G, Jolles J. Differences in cognitive performance during pregnancy and early motherhood. Psychol Med 2006; 36: 1023-1032.

75 Buckwalter JG, Stanczyk FZ, McCleary CA, Bluestein BW, Buckwalter DK, Rankin KP, Chang L, Goodwin TM. Pregnancy, the postpartum, and steroid hormones: effects on cognition and mood. Psychoneuroendocrinology 1999; 24: 69-84.

76 Bannbers E, Gingnell M, Engman J, Morell A, Sylven S, Skalkidou A, Kask K, Backstrom T, Wikstrom J, Poromaa IS. Prefrontal activity during response inhibition decreases over time in the postpartum period. Behav Brain Res 2013; 241: 132-138.

77 Amin Z, Epperson CN, Constable RT, Canli T. Effects of estrogen variation on neural correlates of emotional response inhibition. Neurolmage 2006; 32: 457-464.

78 Swain JE, Kim P, Ho SS. Neuroendocrinology of parental response to baby-cry. J Neuroendocrinol 2011; 23: 1036-1041.

79 Swain JE, Mayes LC, Leckman JF. The development of parent-infant attachment through dynamic and interactive signaling loops of care and cry. Behav Brain Sci 2004; 27: 472-473.

80 Robbins TW, Everitt BJ. Motivation and Reward. In: Squire LR, Bloom FE, McConnell SK, Roberts JL, Spitzer NC, Zigmond MJ, eds. Fundamental Neuroscience. San Diego: Elsevier Science, 2003; 1109-1126.

81 Schultz W. Dopamine neurons and their role in reward mechanisms. Curr Opin Neurobiol 1997; 7: 191-197.

82 Schultz W. Behavioral theories and the neurophysiology of reward. Annu Rev Psychol 2006; 57: 87-115.

83 Delgado MR, Locke HM, Stenger VA, Fiez JA. Dorsal striatum responses to reward and punishment: effects of valence and magnitude manipulations. Cogn Affect Behav Neurosci 2003; 3: 27-38.

84 O'Doherty JP. Reward representations and reward-related learning in the human brain: insights from neuroimaging. Curr Opin Neurobiol 2004; 14: 769-776.

85 Forbes EE, Dahl RE. Neural systems of positive affect: relevance to understanding child and adolescent depression? Dev Psychopathol 2005; 17: 827-850.

86 Dunlop BW, Nemeroff CB. The role of dopamine in the pathophysiology of depression. Arch Gen Psych 2007; 64: 327-337.

87 Pizzagalli DA, Holmes AJ, Dillon DG, Goetz EL, Birk JL, Bogdan R, Dougherty DD, losifescu DV, Rauch SL, Fava M. Reduced caudate and nucleus accumbens response to rewards in unmedicated individuals with major depressive disorder. Am J Psychiatry 2009; 166: 702-710.

88 Forbes EE, Hariri AR, Martin SL, Silk JS, Moyles DL, Fisher PM, Brown SM, Ryan ND, Birmaher B, Axelson DA, Dahl RE. Altered striatal activation predicting real-world positive affect in adolescent major depressive disorder. Am J Psychiatry 2009; 166: 64-73.

89 Keedwell PA, Andrew C, Williams SC, Brammer MJ, Phillips ML. The neural correlates of anhedonia in major depressive disorder. Biol Psychiatry 2005; 58: 843-853.

90 Lawrence NS, Williams AM, Surguladze S, Giampietro V, Brammer MJ, Andrew C, Frangou S, Ecker C, Phillips ML. Subcortical and ventral prefrontal cortical neural responses to facial expressions distinguish patients with bipolar disorder and major depression. Biol Psychiatry 2004; 55: 578-587.

91 Epstein J, Pan H, Kocsis JH, Yang Y, Butler T, Chusid J, Hochberg H, Murrough J, Strohmayer $E_{1}$ Stern E, Silbersweig DA. Lack of ventral striatal response to positive stimuli in depressed versus normal subjects. Am J Psychiatry 2006; 163: 1784-1790. 
92 Mourao-Miranda J, Oliveira L, Ladouceur CD, Marquand A, Brammer $M$, Birmaher $B$, Axelson $D$, Phillips ML. Pattern recognition and functional neuroimaging help to discriminate healthy adolescents at risk for mood disorders from low risk adolescents. PLOS ONE 2012; 7: e29482.

93 Keedwell PA, Andrew C, Williams SC, Brammer MJ, Phillips ML. A double dissociation of ventromedial prefrontal cortical responses to sad and happy stimuli in depressed and healthy individuals. Biol Psychiatry 2005; 58: 495-503.

94 Moses-Kolko EL, Meltzer CC, Berga SL, Wisner KL. Postpartum depression: the clinical disorder and application of PET imaging research methods. In: Bridges RS, ed. Neurobiology of the Parental Brain. Burlington: Academic Press, 2008; 175-199.

95 Champagne FA, Chretien P, Stevenson CW, Zhang TY, Gratton A, Meaney MJ. Variations in nucleus accumbens dopamine associated with individual differences in maternal behavior in the rat. $J$ Neurosci 2004; 24: 4113-4123.

96 Ferris $C F$, Kulkarni $P$, Sullivan JM Jr, Harder JA, Messenger TL, Febo M. Pup suckling is more rewarding than cocaine: evidence from functional magnetic resonance imaging and three-dimensional computational analysis. J Neurosci 2005; 25: 149-156.

97 Shahrokh DK, Zhang TY, Diorio J, Gratton A, Meaney MJ. Oxytocindopamine interactions mediate variations in maternal behavior in the rat. Endocrinology 2010; 151: 2276-2286.

98 Pavesi E, Enck MC, De Toledo CAB, Terenzi MG. Disruption of maternal behaviour by acute conspecific interaction induces selective activation of the lateral periaqueductal grey. Eur J Neurosci 2007; 26: 20552065.

99 Sukikara MH, Mota-Ortiz SR, Baldo MV, Felicio LF, Canteras NS. The periaqueductal gray and its potential role in maternal behavior inhibition in response to predatory threats. Behav Brain Res 2010; 209: 226-233.

100 Nephew BC, Caffrey MK, Felix-Ortiz AC, Ferris CF, Febo M. Blood oxygen level-dependent signal responses in corticolimbic 'emotions' circuitry of lactating rats facing intruder threat to pups. Eur J Neurosci 2009; 30: 934-945.

101 Ranote S, Elliott R, Abel KM, Mitchell R, Deakin JFW, Appleby L. The neural basis of maternal responsiveness to infants: an fMRI study. NeuroReport 2004; 15: 1825-1829.

102 Nitschke JB, Nelson EE, Rusch BD, Fox AS, Oakes TR, Davidson RJ. Orbitofrontal cortex tracks positive mood in mothers viewing pictures of their newborn infants. Neuroimage 2004; 21: 583-592.

103 Wieck A, Kumar R, Hirst AD, Marks MN, Campbell IC, Checkley SA. Increased sensitivity of dopamine receptors and recurrence of affective psychosis after childbirth. Br Med J 1991; 303: 613-616.

104 Moses-Kolko EL, Price JC, Wisner KL, Hanusa BH, Meltzer CC, Berga SL, Grace AA, di Scalea TL, Kaye WH, Becker C, Drevets WC. Postpartum and depression status are associated with lower [(11)C]raclopride BP (ND) in reproductive-age women. Neuropsychopharmacology 2012; 37: 1422-1432.

105 Moses-Kolko EL, Fraser D, Wisner KL, James JA, Saul AT, Fiez JA, Phillips ML. Rapid habituation of ventral striatal response to reward receipt in postpartum depression. Biol Psychiatry 2011; 70: 395-399.

106 Frith U, Frith CD. Development and neurophysiology of mentalizing. Philos Trans R Soc Lond B Biol Sci 2003; 358: 459-473.

107 Hein G, Singer T. I feel how you feel but not always: the empathic brain and its modulation. Curr Opin Neurobiol 2008; 18: 153-158.

108 Gallese V, Keysers C, Rizzolatti G. A unifying view of the basis of social cognition. Trends Cogn Sci 2004; 8: 396-403.

109 Uddin LQ, lacoboni M, Lange C, Keenan JP. The self and social cognition: the role of cortical midline structures and mirror neurons. Trends Cogn Sci 2007; 11: 153-157.
110 lacoboni M. Neurobiology of imitation. Curr Opin Neurobiol 2009; 19: 661-665.

111 Bernhardt BC, Singer T. The neural basis of empathy. Annu Rev Neurosci 2012; 35: 1-23.

112 Frith $C D$, Frith $U$. The neural basis of mentalizing. Neuron 2006; 50 : 531-534.

113 Mitchell JP. Inferences about mental states. Philos Trans $R$ Soc Lond $B$ Biol Sci 2009; 364: 1309-1316.

114 Lenzi D, Trentini C, Pantano P, Macaluso E, lacoboni M, Lenzi GL, Ammaniti M. Neural basis of maternal communication and emotional expression processing during infant preverbal stage. Cereb Cortex 2009; 19: 1124-1133.

115 Eisenberger NI, Cole SW. Social neuroscience and health: neurophysiological mechanisms linking social ties with physical health. Nat Neurosci 2012; 15: 669-674.

116 Poulin MJ, Brown SL, Dillard AJ, Smith DM. Giving to others and the association between stress and mortality. Am J Public Health 2013; 103: 1649-1655.

117 Bowlby J. Loss: Sadness and Depression, vol. 3. New York: Basic Books, 1980.

118 Meaney MJ. Maternal care, gene expression, and the transmission of individual differences in stress reactivity across generations. Annu Rev Neurosci 2001; 24: 1161-1192.

119 Buss C, Lord C, Wadiwalla M, Hellhammer DH, Lupien SJ, Meaney MJ, Pruessner JC. Maternal care modulates the relationship between prenatal risk and hippocampal volume in women but not in men. $J$ Neurosci 2007; 27: 2592-2595.

120 Kim P, Leckman JF, Mayes LC, Newman MA, Feldman R, Swain JE. Perceived quality of maternal care in childhood and structure and function of mothers' brain. Dev Sci 2010; 13: 662-673.

121 Beckes L, Coan JA. Social baseline theory: the role of social proximity in emotion and economy of action. Soc Pers Psychol Compass 2011; 5: 976-988.

122 Coan JA, Schaefer HS, Davidson RJ. Lending a hand: social regulation of the neural response to threat. Psychol Sci 2006; 17: 1032-1039.

123 Hyde LW, Gorka A, Manuck SB, Hariri AR. Perceived social support moderates the link between threat-related amygdala reactivity and trait anxiety. Neuropsychologia 2011; 49: 651-656.

124 Insel TR. A neurobiological basis of social attachment. Am J Psychiatry 1997; 154: 726-735.

125 Atzil $S$, Hendler T, Feldman R. Specifying the neurobiological basis of human attachment: brain, hormones, and behavior in synchronous and intrusive mothers. Neuropsychopharmacology 2011; 36: 2603-2615.

126 Atzil S, Hendler T, Zagoory-Sharon 0, Winetraub Y, Feldman R. Synchrony and specificity in the maternal and the paternal brain: relations to oxytocin and vasopressin. J Am Acad Child Adolesc Psychiatry 2012; 51: 798-811.

127 Molitor A, Mayes LC. Problematic dyadic interaction among toddlers and their polydrug-cocaine-using mothers. Infant Ment Health J 2010; 31: 121-140.

128 Landi N, Montoya J, Kober H, Rutherford HJ, Mencl WE, Worhunsky PD, Potenza MN, Mayes LC. Maternal neural responses to infant cries and faces: relationships with substance use. Front Psychiatry; 2011; $2: 32$.

129 Swain J, Ho S, Rosenblum K, Marcus S, Muzik M Maternal Brain Physiology in Health, Mood Disorders and Opiate Exposure. Paper presented at: 60th American Academy of Child and Adolescent Psychiatry 2013; Orlando, FL.

130 Fox MD, Raichle ME. Spontaneous fluctuations in brain activity observed with functional magnetic resonance imaging. Nat Rev Neurosci 2007; 8: 700-711. 
131 Shulman GL, Corbetta M, Fiez JA, Buckner RL, Miezin FM, Raichle ME, Petersen SE. Searching for activations that generalize over tasks. Hum Brain Mapp 1997; 5: 317-322.

132 Mazoyer B, Zago L, Mellet E, Bricogne S, Etard O, Houde O, Crivello F, Joliot M, Petit L, Tzourio-Mazoyer N. Cortical networks for working memory and executive functions sustain the conscious resting state in man. Brain Res Bull 2001; 54: 287-298.

133 Greicius MD, Krasnow B, Reiss AL, Menon V. Functional connectivity in the resting brain: a network analysis of the default mode hypothesis. Proc Natl Acad Sci USA2003; 100: 253-258.

134 Menon V. Large-scale brain networks and psychopathology: a unifying triple network model. Trends Cogn Sci 2011; 15: 483-506.

135 Buckner RL, Andrews-Hanna JR, Schacter DL. The brain's default network: anatomy, function, and relevance to disease. Ann N Y Acad Sci 2008; 1124: 1-38.

136 Johnson MK, Raye CL, Mitchell KJ, Touryan SR, Greene EJ, Nolen-Hoeksema S. Dissociating medial frontal and posterior cingulate activity during self-reflection. Soc Cogn Affect Neurosci 2006; 1: 56-64.

137 Northoff G, Heinzel A, de Greck M, Bermpohl F, Dobrowolny H, Panksepp J. Self-referential processing in our brain-a meta-analysis of imaging studies on the self. Neurolmage 2006; 31: 440-457.

138 Greicius MD, Flores BH, Menon V, Glover GH, Solvason HB, Kenna H, Reiss AL, Schatzberg AF. Resting-state functional connectivity in major depression: abnormally increased contributions from subgenual cingulate cortex and thalamus. Biol Psychiatry 2007; 62: 429-437.

139 Berman MG, Peltier S, Nee DE, Kross E, Deldin PJ, Jonides J. Depression, rumination and the default network. Soc Cogn Affect Neurosci 2011; 6: 548-555.

140 Sheline YI, Price JL, Yan Z, Mintun MA. Resting-state functional MRI in depression unmasks increased connectivity between networks via the dorsal nexus. Proc Natl Acad Sci USA 2010; 107: 11020-11025.

141 Hamilton JP, Furman DJ, Chang C, Thomason ME, Dennis E, Gotlib IH. Default-mode and task-positive network activity in major depressive disorder: implications for adaptive and maladaptive rumination. Biol Psychiatry 2011; 70: 327-333.

142 Hamilton JP, Glover GH, Hsu JJ, Johnson RF, Gotlib IH. Modulation of subgenual anterior cingulate cortex activity with real-time neurofeedback. Hum Brain Mapp 2011; 32: 22-31.

143 Johnson MK, Nolen-Hoeksema S, Mitchell KJ, Levin Y. Medial cortex activity, self-reflection and depression. Soc Cogn Affect Neurosci 2009; 4: 313-327.

144 Chase HW, Moses-Kolko EL, Zevallos C, Wisner KL, Phillips ML. Disrupted posterior cingulate-amygdala connectivity in postpartum depressed women as measured with resting BOLD fMRI. Soc Cogn Affect Neurosci 2013; 9: 1069-1075.

145 Mars RB, Neubert FX, Noonan MP, Sallet J, Toni I, Rushworth MF. On the relationship between the "default mode network" and the "social brain". Front Hum Neurosci 2012; 6: 189

146 Deligiannidis KM, Sikoglu EM, Shaffer SA, Frederick B, Svenson AE, Kopoyan A, Kosma CA, Rothschild AJ, Moore CM. GABAergic neuroactive steroids and resting-state functional connectivity in postpartum depression: a preliminary study. J Psychiatr Res 2013; 47: 816-828.

147 Xiao-juan W, Jian W, Zhi-hong L, Yan M, Shi-wei Z. Increased posterior cingulate, medial frontal and decreased temporal regional homogeneity in depressed mothers. Procedia Environ Sci 2011; 8: 737-743.

148 Huprich SK, Pouliot GS, Bruner R. Self-other representations mediate the relationship between Five-Factor Model depression and depressive states. Psychiatry 2012; 75: 176-189.

149 Bifulco A, Kwon J, Jacobs C, Moran PM, Bunn A, Beer N. Adult attachment style as mediator between childhood neglect/abuse and adult depression and anxiety. Soc Psychiatry Psychiatr Epidemiol 2006; 41: 796-805.
150 Fonagy $\mathrm{P}$, Leigh $\mathrm{T}$, Steele $\mathrm{M}$, Steele $\mathrm{H}_{1}$ Kennedy $\mathrm{R}$, Mattoon $\mathrm{G}$, Target $M$, Gerber A. The relation of attachment status, psychiatric classification, and response to psychotherapy. J Consult Clin Psychol 1996; 64: 22-31.

151 Fonagy $P$, Steele $H$, Steele M. Maternal representations of attachment during pregnancy predict the organization of infant-mother attachment at one year of age. Child Dev 1991; 62: 891-905.

152 Van IJzendoorn MH. Adult attachment representations, parental responsiveness, and infant attachment: a meta-analysis on the predictive validity of the Adult Attachment Interview. Psychol Bull 1995; 117: 387-403.

153 Mayes LC, Swain JE, Leckman JF. Parental attachment systems: neural circuits, genes, and experiential contributions to parental engagement. Clin Neurosci Res 2005; 4: 301-313.

154 Swain JE. The human parental brain: in vivo neuroimaging. Prog Neuropsychopharmacol Biol Psychiatry 2011; 35: 1242-1254.

155 Swain JE, Konrath S, Brown SL, Finegood ED, Akce LB, Dayton CJ, Ho SS. Parenting and beyond: common neurocircuits underlying parental and altruistic caregiving. Parent Sci Pract 2012; 12: 115-123.

156 Laurent HK, Ablow JC. The missing link: mothers' neural response to infant cry related to infant attachment behaviors. Infant Behav Dev 2012; 35: 761-772.

157 Musser ED, Kaiser-Laurent H, Ablow JC. The neural correlates of maternal sensitivity: an fMRI study. Dev Cogn Neurosci 2012; 2: 428-436.

158 Lemche E, Giampietro VP, Surguladze SA, Amaro EJ, Andrew CM, Williams SC, Brammer MJ, Lawrence N, Maier MA, Russell TA, Simmons A, Ecker $C$, Joraschky $P$, Phillips ML. Human attachment security is mediated by the amygdala: evidence from combined fMRI and psychophysiological measures. Hum Brain Mapp 2006; 27: 623-635.

159 Wan MW, Downey D, Strachan H, Elliott R, Williams SR, Abel KM. The neural basis of maternal bonding. PLOS ONE 2014; 9: e88436.

160 Maccari S, Morley-Fletcher S, Szyf M. The consequences of early life adversity: neurobiological, behavioural and epigenetic adaptations. J Neuroendocrinol 2014; 26: 707-723.

161 Lupien SJ, McEwen BS, Gunnar MR, Heim C. Effects of stress throughout the lifespan on the brain, behaviour and cognition. Nat Rev Neurosci 2009; 10: 434-445.

162 Clark DA, Beck AT, Stewart B. Cognitive specificity and positive-negative affectivity: complementary or contradictory views on anxiety and depression? J Abnorm Psychol 1990; 99: 148-155.

163 Gotlib IH, Whiffen VE, Wallace PM, Mount JH. Prospective investigation of postpartum depression: factors involved in onset and recovery. $J$ Abnorm Psychol 1991; 100: 122-132.

164 Kim P, Evans GW, Angstadt M, Ho SS, Sripada CS, Swain JE, Liberzon I, Phan KL. Effects of childhood poverty and chronic stress on emotion regulatory brain function in adulthood. Proc Natl Acad Sci USA 2013; 110: 18442-18447.

165 Kinsley CH, Lambert KG. Reproduction-induced neuroplasticity: natural behavioural and neuronal alterations associated with the production and care of offspring. J Neuroendocrinol 2008; 20: 515-525.

166 Galea LA, Leuner B, Slattery D. Hippocampal plasticity during the peripartum period: influence of sex steroids, stress and ageing. J Neuroendocrinol 2014; 26: 641-648.

167 Lonstein JS, Maguire J, Meinlschmidt G, Neumann I. Emotion and mood adaptations in the peripartum female: complementary contributions of gamma-aminobutyric acid and oxytocin. J Neuroendocrinol 2014; 26: 649-664.

168 Numan $M_{1}$ Insel TR. Neurochemistry and molecular biology of maternal behavior. In: Numan $M_{1}$ Insel TR, eds. The Neurobiology of Parental Behavior, vol. 1. New York: Springer-Verlag, 2003; 190-245.

169 Chong S, Vickaryous N, Ashe A, Zamudio N, Youngson N, Hemley S, Stopka T, Skoultchi A, Matthews J, Scott HS, de Kretser D, O'Bryan M, 
Blewitt $M$, Whitelaw E. Modifiers of epigenetic reprogramming show paternal effects in the mouse. Nat Genet 2007; 39: 614-622.

170 Dietz DM, Laplant Q, Watts EL, Hodes GE, Russo SJ, Feng J, Oosting RS, Vialou V, Nestler EJ. Paternal transmission of stress-induced pathologies. Biol Psychiatry 2011; 70: 408-414.

171 Dietz DM, Nestler EJ. From father to offspring: paternal transmission of depressive-like behaviors. Neuropsychopharmacology 2012; 37: 311-312.

172 Belsky JJSR, Sligo J, Woodward L, Silva PA. Intergenerational transmission of warm-sensitive-stimulating parenting: a prospective study of mothers and fathers of 3-year-olds. Child Dev 2005; 76: 384-396.

173 Fleming AS, Kraemer GW, Gonzalez A, Lovic V, Rees S, Melo A. Mothering begets mothering: the transmission of behavior and its neurobiology across generations. Pharmacol Biochem Behav 2002; 73: $61-75$.

174 Maestripieri D. Early experience affects the intergenerational transmission of infant abuse in rhesus monkeys. Proc Natl Acad Sci USA 2005; 102: 9726-9729.

175 Champagne F, Meaney MJ. Like mother, like daughter: evidence for non-genomic transmission of parental behavior and stress responsivity. Prog Brain Res 2001; 133: 287-302.

176 Knutson JF. Psychological characteristics of maltreated children: putative risk factors and consequences. Annu Rev Psychol 1995; 46: 401431.

177 Benoit D, Parker KC. Stability and transmission of attachment across three generations. Child Dev 1994; 65: 1444-1456.

178 Benoit D, Parker KC, Zeanah CH. Mothers' representations of their infants assessed prenatally: stability and association with infants' attachment classifications. J Child Psychol Psychiatry 1997; 38: 307313.

179 Miller L, Kramer R, Warner V, Wickramaratne P, Weissman M. Intergenerational transmission of parental bonding among women. J Am Acad Child Adolesc Psychiatry 1997; 36: 1134-1139.

180 Serbin LA, Karp J. The intergenerational transfer of psychosocial risk: mediators of vulnerability and resilience. Annu Rev Psychol 2004; 55: 333-363.

181 Van ljzendoorn MH. Intergenerational transmission of attachment. Int J Psychol 1992; 27: 208-208.

182 Moehler E, Biringen Z, Poustka L. Emotional availability in a sample of mothers with a history of abuse. Am J Orthopsychiatry 2007; 77: 624628.

183 Herrenkohl TI, Kosterman R, Mason WA, Hawkins JD, McCarty CA, McCauley E. Effects of childhood conduct problems and family adversity on health, health behaviors, and service use in early adulthood: tests of developmental pathways involving adolescent risk taking and depression. Dev Psychopathol 2010; 22: 655-665.

184 Martin G, Bergen HA, Roeger L, Allison S. Depression in young adolescents - Investigations using 2 and 3 factor versions of the parental bonding instrument. J Nerv Ment Dis 2004; 192: 650-657.

185 Rey JM. Perceptions of poor maternal-care are associated with adolescent depression. J Affect Disord 1995; 34: 95-100.

186 Enns MW, Cox BJ, Clara I. Parental bonding and adult psychopathology: results from the US National Comorbidity Survey. Psychol Med 2002; 32: 997-1008.

187 Putnam FW. Ten-year research update review: child sexual abuse. J Am Acad Child Adolesc Psychiatry 2003; 42: 269-278.

188 Spertus IL, Yehuda R, Wong CM, Halligan S, Seremetis SV. Childhood emotional abuse and neglect as predictors of psychological and physical symptoms in women presenting to a primary care practice. Child Abuse Negl 2003; 27: 1247-1258.

189 Jaffee SR, Caspi A, Moffitt TE, Polo-Tomas M, Taylor A. Individual, family, and neighborhood factors distinguish resilient from non-resili- ent maltreated children: a cumulative stressors model. Child Abuse Negl 2007; 31: 231-253.

190 Hankin BL, Nederhof E, Oppenheimer CW, Jenness J, Young JF, Abela JRZ, Smolen A, Ormel J, Oldehinkel AJ. Differential susceptibility in youth: evidence that $5-H T T L R \times$ positive parenting is associated with positive affect 'for better and worse'. Transl Psychiat 2011; 1: e44.

191 Oppenheimer CW, Hankin BL, Jenness JL, Young JF, Smolen A. Observed positive parenting behaviors and youth genotype: evidence for geneenvironment correlations and moderation by parent personality traits. Dev Psychopathol 2013; 25: 175-191.

192 Kaufman J, Yang BZ, Douglas-Palumberi H, Houshyar S, Lipschitz D, Krystal JH, Gelernter J. Social supports and serotonin transporter gene moderate depression in maltreated children. Proc Natl Acad Sci USA 2004; 101: 17316-17321.

193 Wind TW, Silvern L. Parenting and family stress as mediators of the long-term effects of child-abuse. Child Abuse Negl 1994; 18: 439-453.

194 Seeman TE, Singer BH, Ryff CD, Love GD, Levy-Storms L. Social relationships, gender, and allostatic load across two age cohorts. Psychosom Med 2002; 64: 395-406.

195 Francis DD, Diorio J, Liu D, Meaney MJ. Nongenomic transmission across generations of maternal behavior and stress responses in the rat. Science 1999; 286: 1155-1158.

196 Dawson G, Ashman SB, Carver $\sqcup$. The role of early experience in shaping behavioral and brain development and its implications for social policy. Dev Psychopathol 2000; 12: 695-712.

197 Segman RH, Goltser-Dubner T, Weiner I, Canetti L, Galili-Weisstub E, Milwidsky A, Pablov V, Friedman N, Hochner-Celnikier D. Blood mononuclear cell gene expression signature of postpartum depression. Mol Psychiatry 2010; 15: 102.

198 Mahon PB, Payne JL, Mackinnon DF, Mondimore FM, Goes FS, Schweizer $B$, Jancic D, Consortium NGIBD, Bi GSC, Coryell WH, Holmans PA, Shi J, Knowles JA, Scheftner WA, Weissman MM, Levinson DF, DePaulo $J R$ Jr, Zandi PP, Potash JB. Genome-wide linkage and follow-up association study of postpartum mood symptoms. Am J Psychiatry 2009; 166: 1229-1237.

199 O'Hara MW, McCabe JE. Postpartum depression: current status and future directions. Annu Rev Clin Psychol 2013; 9: 379-407.

200 Cooper PJ, Murray L. Course and recurrence of postnatal depression evidence for the specificity of the diagnostic concept. Br J Psychiatry 1995; 166: 191-195.

201 Altemus M, Neeb CC, Davis A, Occhiogrosso M, Nguyen T, Bleiberg KL. Phenotypic differences between pregnancy-onset and postpartumonset major depressive disorder. J Clin Psychiatry 2012; 73: e1485e1491.

202 Carter FA, Frampton CM, Mulder RT. Cesarean section and postpartum depression: a review of the evidence examining the link. Psychosom Med 2006; 68: 321-330.

203 Dennis CL, McQueen K. The relationship between infant-feeding outcomes and postpartum depression: a qualitative systematic review. Pediatrics 2009; 123: e736-e751.

204 Stuebe AM, Grewen K, Pedersen CA, Propper C, Meltzer-Brody S. Failed lactation and perinatal depression: common problems with shared neuroendocrine mechanisms? J Women's Health 2012; 21: 264-272.

205 O'Hara MW, Schlechte JA, Lewis DA, Wright EJ. Prospective study of postpartum blues. Biologic and psychosocial factors. Arch Gen Psychiatry 1991; 48: 801-806.

206 Workman JL, Barha CK, Galea LAM. Endocrine substrates of cognitive and affective changes during pregnancy and postpartum. Behav Neurosci 2012; 126: 54-72.

207 Bloch M, Rubinow DR, Schmidt PJ, Lotsikas A, Chrousos GP, Cizza G. Cortisol response to ovine corticotropin-releasing hormone in a model of pregnancy and parturition in euthymic women with and without a 
history of postpartum depression. J Clin Endocr Metab 2005; 90: 695699.

208 Brummelte S, Galea LA. Depression during pregnancy and postpartum: contribution of stress and ovarian hormones. Prog Neuropsychopharmacol Biol Psychiatry 2010; 34: 766-776.

209 Meltzer-Brody S, Stuebe A, Dole N, Savitz D, Rubinow D, Thorp J. Elevated corticotropin releasing hormone $(\mathrm{CRH})$ during pregnancy and risk of postpartum depression (PPD). J Clin Endocrinol Metab 2011; 96: E40-E47.

210 Bloch M, Schmidt PJ, Danaceau M, Murphy J, Nieman L, Rubinow DR. Effects of gonadal steroids in women with a history of postpartum depression. Am J Psychiatry 2000; 157: 924-930.

211 Bloch M, Daly RC, Rubinow DR. Endocrine factors in the etiology of postpartum depression. Compr Psychiatry 2003; 44: 234-246.

212 Daly RC, Kim MY, Bloch M, Schmidt PJ, Purdy RM, Rubinow DR. Neurosteroids in reproductive endocrine-related mood disorders. Biol Psychiatry 2000; 47: 5S-5S.

213 Schiller CE, O'Hara MW, Johnson AK, Rubinow DR. Estradiol withdrawal triggers postpartum depression across species. Biol Psychiatry 2012; 71: 279s-279s.

214 Schiller CE, O'Hara MW, Rubinow DR, Johnson AK. Estradiol modulates anhedonia and behavioral despair in rats and negative affect in a subgroup of women at high risk for postpartum depression. Physiol Behav 2013; 119: 137-144.
215 Moses-Kolko EL, Berga SL, Kalro B, Sit DKY, Wisner KL. Transdermal estradiol for postpartum depression: a promising treatment option. Clin Obstet Gynecol 2009; 52: 516-529.

216 Ho SS, Konrath S, Brown S, Swain JE. Empathy and stress related neural responses in maternal decision making. Front Neurosci 2014; 8: 152.

217 Wisner KL, Hanusa BH, Perel JM, Peindl KS, Piontek CM, Sit DKY, Findling RL, Moses-Kolko EL. Postpartum depression: a randomized trial of sertraline vs nortriptyline. J Clin Psychopharmacol 2006; 26: 353-360.

218 Sacher J, Wilson AA, Houle S, Rusjan P, Hassan S, Bloomfield PM, Stewart DE, Meyer JH. Elevated brain monoamine oxidase a binding in the early postpartum period. Arch Gen Psychiatry 2010; 67: 468-474.

219 Van Essen DC, Ugurbil K. The future of the human connectome. NeuroImage 2012; 62: 1299-1310.

220 Soper D The free statistics calculators website. 2010; http://www. danielsoper.com/statcalc.

221 Miller GA, Rockstroh B. Endophenotypes in psychopathology research: where do we stand? Ann Rev Clin Psychol 2013; 9: 177-213.

222 Phillips ML, Ladoucer CD, Drevets WC. A neural model of voluntary and automatic emotion regulation: implications for understanding the pathophysiology and neurodevelopment of bipolar disorder. Mol Psychiatry 2008; 13: 833-857. 